\title{
DEVELOPMENT OF PROBABILISTIC UNCERTAINTY ANALYSIS METHODOLOGY FOR SRS PERFORMANCE ASSESSMENTS MAINTENANCE PLAN ACTIVITIES
}

Prepared by:

James R. Cook

Leonard B. Collard

Gregory P. Flach

Patricia L. Lee

March 8, 2002

Rev. 0

Westinghouse Savannah River Company

Savannah River Site

Aiken, SC 29808

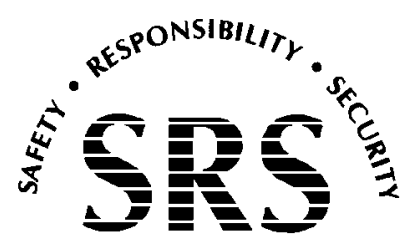

Prepared for the U.S. Department of Energy Under

Contract Number DE-AC09-96SR18500 
This document was prepared in conjunction with work accomplished under Contract No. DE-AC09-96SR18500 with the U. S. Department of Energy.

\section{DISCLAIMER}

This report was prepared as an account of work sponsored by an agency of the United States Government. Neither the United States Government nor any agency thereof, nor any of their employees, makes any warranty, express or implied, or assumes any legal liability or responsibility for the accuracy, completeness, or usefulness of any information, apparatus, product or process disclosed, or represents that its use would not infringe privately owned rights. Reference herein to any specific commercial product, process or service by trade name, trademark, manufacturer, or otherwise does not necessarily constitute or imply its endorsement, recommendation, or favoring by the United States Government or any agency thereof. The views and opinions of authors expressed herein do not necessarily state or reflect those of the United States Government or any agency thereof.

This report has been reproduced directly from the best available copy.

Available for sale to the public, in paper, from: U.S. Department of Commerce, National Technical Information Service, 5285 Port Royal Road, Springfield, VA 22161, phone: (800) 553-6847, fax: (703) 605-6900

email: orders@ntis.fedworld.gov

online ordering: http://www.ntis.gov/help/index.asp

Available electronically at http://www.osti.gov/bridge

Available for a processing fee to U.S. Department of Energy and its contractors, in paper, from: U.S. Department of Energy, Office of Scientific and Technical Information, P.O. Box 62, Oak Ridge, TN 37831-0062,

phone: (865)576-8401,

fax: (865)576-5728

email: $\underline{\text { reports@ adonis.osti.gov }}$ 


\section{REVIEWS AND APPROVALS}

Author

James R. Cook, Waste Disposal and Environmental Development

Date

Elmer L. Wilhite, Design Check

Date

SRTC Approvals/Review

B.T. Butcher, Level 4 Manager, Waste Processing Technology

Date

W.E. Stevens, Level 3 Manager, Waste Processing Technology

Date

Solid Waste Division Approval

W.T. Goldston, Solid Waste Planning and Technology

Date 


\section{TABLE OF CONTENTS}

LIST OF TABLES

LIST OF FIGURES

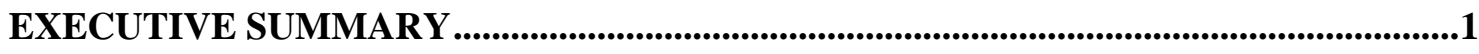

INTRODUCTION

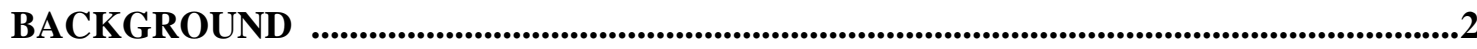

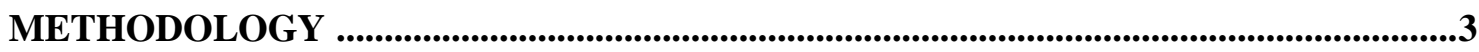

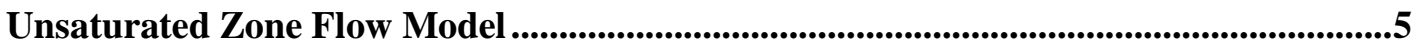

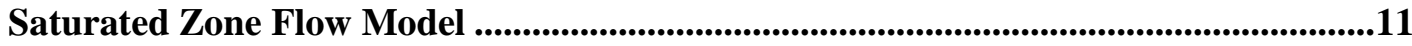

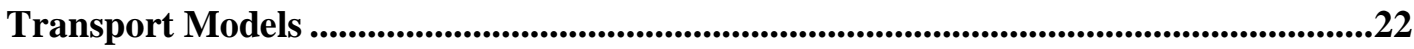

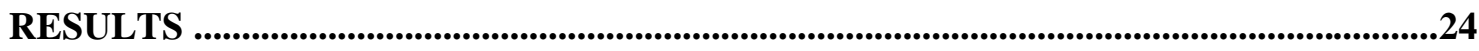

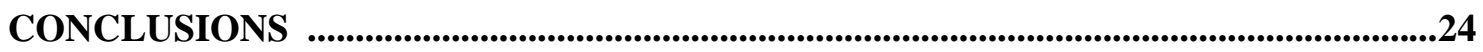

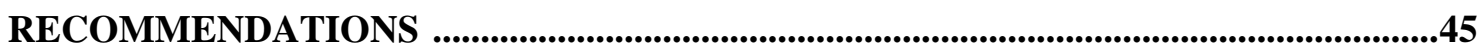

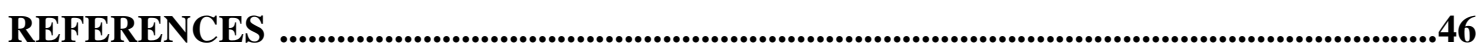




\section{LIST OF TABLES}

Table 1. Advisory Team membership.........................................................................................3

Table 2. Parameters in the performance assessment model with natural variability ..........4

Table 3. Monte Carlo runs for PA saturated flow model .........................................................17

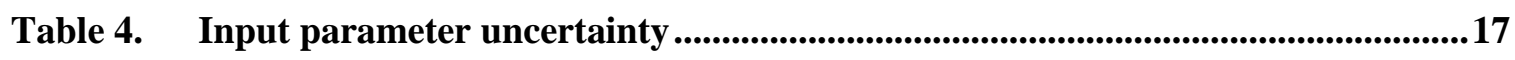

Table 5. Calibration results for Monte Carlo runs ..........................................................18

Table 6. Distribution parameters for sampled sand and clay $K_{d} s$........................................22

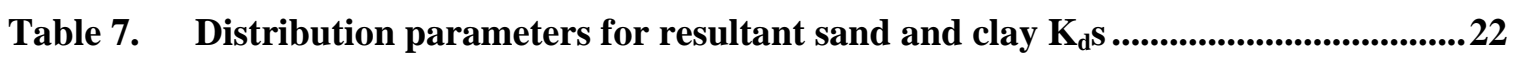

Table 8. Case by case parameters and results .....................................................................44 


\section{LIST OF FIGURES}

Figure 1. Probability density function of infiltration.................................................................6

Figure 2. Infiltration - 10,000 random samples in 100 bins....................................................... 7

Figure 3. Probability distribution functions of cap performance times.....................................8

Figure 4. Probability distribution function of native soil saturated hydraulic conductivity .............................................................................................................................9

Figure 5. Probability distribution function of native soil porosity ..........................................12

Figure 6. Soil suction versus saturation for native soil ...................................................................13

Figure 7. Relative hydraulic conductivity versus saturation for native soil .........................14

Figure 8. Illustration of three-point mid-point Latin Hypercube Sampling for a unit normal distribution and three definitions of the midpoint ........................................15

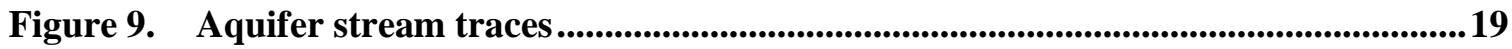

Figure 10. Probability distribution functions for iodine and strontium $K_{d} s$.........................23

Figure 11. Probability distribution function of native soil I-129 $\mathrm{K}_{\mathrm{d} \text {................................................................ }}$

Figure 12. Probability distribution function of native soil $\mathrm{Sr}-90 \mathrm{~K}_{\mathrm{d}}$..................................................... 26

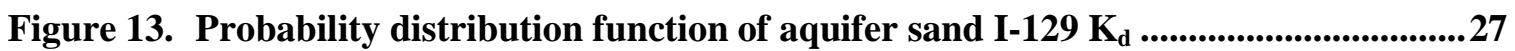

Figure 14. Probability distribution function of aquifer clay $I-129 \mathrm{~K}_{\mathrm{d}}$......................................28

Figure 15. Probability distribution function of aquifer sand $\mathrm{Sr}-90 \mathrm{~K}_{\mathrm{d}}$....................................29

Figure 16. Probability distribution function of aquifer clay $\mathrm{Sr}-90 \mathrm{~K}_{\mathrm{d}}$...................................30

Figure 17. Probability distribution function of native soil density ........................................31

Figure 18. Cumulative probability function of I-129 peak fractional flux to the water table

Figure 19. Cumulative probability function of Sr-90 peak fractional flux to the water table

Figure 20. Cumulative probability function of I-129 time of peak flux to the water table

Figure 21. Cumulative probability function of Sr-90 time of peak flux to the water table 35

Figure 22. Cumulative probability function of I-129 well concentration versus time ...........36

Figure 23. Cumulative probability function of Sr-90 well concentration versus time...........37

Figure 24. Cumulative probability function of I-129 peak well concentration........................38

Figure 25. Cumulative probability function of I-129 time of peak well concentration.........39

Figure 26. Cumulative probability function of Sr-90 peak well concentration......................40

Figure 27. Cumulative probability function of Sr-90 time of peak well concentration .........41 
THIS PAGE INTENTIONALLY LEFT BLANK

Rev. 0 


\section{EXECUTIVE SUMMARY}

An initial uncertainty analysis of the Performance Assessment (PA) model of the Savannah River Site (SRS) trench disposal unit was conducted. Selected input data values were varied for both flow and transport analyses to generate input sets called realizations. Outputs of fluxes to the water table and well concentrations were compared to results from the PA.

This stage of the uncertainty analysis served as a prototype for future work. The focus was to lay the foundation for a more comprehensive analysis, generate a limited set of output results, and learn about the process and potential problems.

Available field data, literature information and professional judgement were used as bases to vary selected input parameters. Nine sets of flow fields were generated for the vadose zone models. Nine sets of transport results were also generated.

Computer programs were obtained or developed and tested to prepare the data sets. A computer program was developed and tested to vary the primary input file for the PORFLOW program by selecting sample values from the prepared data sets. Recursive batch programs were developed to help automate the process of conducting both the flow and transport analyses.

A data directory hierarchy was developed that created a separate directory for each combined data set or realization. Results for each realization were separated from other results during the flow and transport analyses, then were combined during the post-processing phase to develop the uncertainty results.

The uncertainty results are shown as cumulative distribution functions. These results are sorted in ascending order (e.g., as the well concentration increases) and are then plotted on a graph of cumulative probability versus an output parameter (e.g., well concentration). Four sets of cumulative distribution functions were developed showing peak well concentrations, the time of occurrence of the peak well concentrations, peak contaminant fluxes to the water table, and the time of occurrence of the peak contaminant fluxes to the water table.

At the locations exhibiting the peak well concentrations, the history of well concentrations for each realization were recorded in approximately two-year intervals. A plot of all the histories was generated for comparison with the PA results as another form of uncertainty results.

The study concludes that the computer programs used in the SRS PA process do not easily lend themselves to the large number of runs needed for a probabilistic uncertainty analysis. Some very innovative techniques were developed to partially automate the runs, but frequent intervention was required. A total of 2000 man-hours were devoted to the work reported here. Several possibilities to address this problem are suggested. 


\section{INTRODUCTION}

The Implementation Guide for DOE Order 435.1, Section IV.P.2(e), (US DOE, 1999a) states that "the performance assessment shall include a sensitivity/uncertainty analysis." The Order, Manual and associated guidance (US DOE, 1999b) has no requirement for a probabilistic analysis.

As the Performance Assessment/Composite Analysis process has matured, an understanding has developed among the practitioners and the reviewers that a probabilistic uncertainty analysis can be a useful way to learn about the overall disposal system, to identify areas where more research is needed to reduce uncertainties, and to determine whether uncertainties are large enough to affect decisions about disposal system operations.

A probabilistic PA model uses probability distributions to represent variability in significant input parameters and propagates these distributions through numerical models using a statistical sampling algorithm. Probabilistic models can encompass uncertainty in the inventory, in fate and transport processes and in exposure pathways to potential receptors. Probabilistic PA models can also attempt to represent and evaluate all components of uncertainty including natural variability, parameter uncertainty, model uncertainty and scenario uncertainty. The outputs of these models are also probability distributions that, if correctly constructed, represent an expected or "bestestimate" of the performance of a disposal site and the uncertainty associated with that estimate, conditioned on the model assumptions. Probabilistic PA models generally include probabilistically based sensitivity and uncertainty analyses and may include formal methods of uncertainty reduction and measurement of the value of uncertainty reduction. This suite of approaches and methodology is described by numerous names including probabilistic risk assessment, quantitative risk assessment, quantitative uncertainty analysis, uncertainty analysis, risk modeling and/or more simply, probabilistic modeling. There is no clearly agreed upon definition of probabilistic modeling but three components are nearly always at the heart of all probabilistic models: 1) use of probability distributions to describe and represent uncertainty, 2) propagation of uncertainty through statistical sampling of the input parameter distributions and multiple model runs and 3) presentation of model outputs as probability distributions (Crowe, 2002).

The work described here is a first attempt to apply the tools of probabilistic analysis to the SRS PA process. It was undertaken to explore the methodology, and was by design very limited in scope.

\section{BACKGROUND}

The term uncertainty takes on a variety of meanings in everyday and technical usage. In this study, uncertainty refers to a quantitative measure of how confident an analyst is that a nominal or best-estimate value lies within a specified surrounding interval or region. Uncertainty can be expressed deterministically (e.g. conservative physical bounds) or statistically (e.g. probability distribution). A probabilistic approach has been chosen for defining and estimating uncertainties associated with the PA of the E-Area Low-Level Waste Facility (McDowell-Boyer, 2000).

Analyses such as the E-Area PA can be thought of as being comprised of two main parts. The first component is a collection of input data. The second is an overall method or model that produces an output result from the input parameters. Parameter uncertainty refers to incomplete knowledge of the true value of an input parameter. Model uncertainty refers to lack of confidence that the model is a valid representation of the physical system. Both contribute to the 
overall uncertainty of an analysis outcome. The present study focuses on trench disposal operations and estimating PA uncertainty due to input parameter uncertainties. Model uncertainties were not evaluated in this investigation to limit the scope to a more tractable problem.

Given a model and input values with specified uncertainty, a number of statistical methods can be used to define uncertainty in the model output. For complex non-linear models with many inputs, such as the E-Area PA, Monte Carlo simulation is a preferred approach (cf. Morgan and Henrion, 1990). The basic concept is to successively draw a value at random from the distribution of each input, and compute the model outcome for each trial. The resulting collection of outcomes comprises a random sample from the underlying model output distribution, from which sample statistics and confidence intervals can be computed.

A variation on simple random sampling is Latin Hypercube Sampling (LHS). In LHS, the input parameter distribution is subdivided into a number of equal probability intervals, and one sample is randomly drawn from each interval. Hence, LHS is a combination of random and non-random sampling of the distribution. Because LHS produces a more uniform sample, the sample mean and variance converge on the true mean and variance more quickly than simple random sampling, and a smaller sample size can be used to achieve the same level of Monte Carlo precision. However, estimating the level of precision is more difficult with LHS because the samples are not drawn independently. Even more uniform sampling and smaller sample sizes are achieved with midpoint LHS, whereby the median value is taken from each equal probability interval. Note that with midpoint LHS, the sample set is entirely non-random. Because the computational and labor efforts associated with a single PA model run are large, minimizing the number of Monte Carlo trials is critical and LHS is preferred over simple random sampling.

\section{METHODOLOGY}

Advisory Team

The first step in the program was to form an advisory team. The members had individual expertise in areas critical to the program. The members and their area of expertise are listed in Table 1.

Table 1. Advisory Team Membership Name Major Area of Expertise

\begin{tabular}{ll}
\hline \hline Len Collard & PORFLOW Model \\
Jim Cook & Performance Assessment \\
Greg Flach & FACT Model \\
Patricia Lee & Probabilistic Dose Calculations \\
Winchester Smith & PA/CA Process \\
Kevin Tempel & Solid Waste Practices \\
Elmer Wilhite & Regulations and Policy \\
Andy Yu & Unsaturated Flow and Transport \\
\hline \hline
\end{tabular}




\section{Selection of Parameters}

At the first team meeting a decision was made to limit the scope of this study to parameters which have natural variability. This decision eliminated model uncertainty due to parameters that are strictly the choice of the person doing the modeling work, such as the number of grids, or the types of boundary conditions. Of course, all parameters which have natural variability will also have uncertainty due to measurement errors.

A list of naturally variable parameters was developed. This list, divided according to the type of model in which it applies (unsaturated flow, saturated flow, or transport) is shown in Table 2

Table 2. Parameters in the Performance Assessment Model with Natural Variability

Unsaturated flow

infiltration at surface

time of cap placement and failure

Properties of clean backfill (saturated vertical and

horizontal hydraulic conductivity) and moisture

characteristic curves

Properties of waste (saturated vertical and horizontal

hydraulic conductivity) and moisture characteristic

curves

Properties of native soil (saturated vertical and

horizontal hydraulic conductivity) and moisture

characteristic curves

porosity of native soil

porosity of backfill

porosity of waste

Saturated flow

infiltration

vertical conductivity through green clay

vertical conductivity through tan clay

Transport in saturated and unsaturated zones

half-life

partition coefficient $\left(\mathrm{K}_{\mathrm{d}}\right)$

native soil diffusion

native soil dispersivities

native soil total porosity

native soil effective porosity

native soil diffusive porosity

native soil bulk density 


\section{Unsaturated Zone Flow Model}

\section{Infiltration at Surface}

A number of water balance studies have been conducted at or near SRS (Hubbard and Englehardt, 1987; Parizek and Root, 1986; Dennehy and McMahon, 1987) with the general conclusion that natural infiltration is about one-third of average annual precipitation, or $40 \mathrm{~cm}$ per year. A data base containing daily rainfall data for the last 35 years was used to estimate the distribution in the annual infiltration for that same time period by summing each year and dividing by three. This gave a data base with an average of $41.5 \mathrm{~cm} / \mathrm{yr}$ and a standard deviation of $6.7 \mathrm{~cm} / \mathrm{yr}$. These data were used to generate an extreme value distribution with a probability density function (pdf) of:

$$
\begin{aligned}
& f(x)=\frac{1}{\alpha} \bullet z \cdot e^{-z} \quad \text { for }-\infty<x<\infty \\
& \text { where } z=e^{-\left(\frac{x-m}{\alpha}\right)}
\end{aligned}
$$

and $m$ and $\alpha$ are the mode and scale, respectively, of the curve with resultant values of 38.3 and $5.8 \mathrm{~cm} / \mathrm{yr}$, shown if Figure 1. The extreme value distribution is commonly used to describe the largest value of a response over a period of time such as floods, rainfall, and earthquakes (Decisioneering 2000).

Figure 2 shows the infiltration distribution and the values that were selected and used in the unsaturated flow runs. For reference, the value for infiltration used in the PA, $40 \mathrm{~cm} / \mathrm{yr}$, is also shown in this figure.

\section{Times of cap placement and failure}

The Performance Assessment assumed that a closure cap was placed over the disposal units 25 years after waste disposal, that it performed as designed for 100 years, and then degraded to a material with the properties of sand for the remainder of the 10,000 year period of assessment. For the purpose of this work, the time of cap placement was assumed to be a uniform distribution with a range of 5 to 50 . The duration of cap performance was assumed to be a log-normal distribution with a minimum of 100 years and a maximum of 500 years. The distribution for the time for which the PA model was run with a failed cap is 10,000 years minus the uncapped and the capped times. These distributions are shown in Figure 3.

$\underline{\text { Saturated hydraulic conductivity, porosity and moisture characteristic curves for native soil }}$

Twenty-five soil samples were taken within the E-Area disposal units as part of the Vadose Zone Monitoring Program (Holmes-Burns, 2001). Laboratory data from these samples included saturated hydraulic conductivity, porosity, and soil moisture versus capillary suction determinations. The saturated hydraulic conductivity and porosity data are shown in Figures 4 and 5. These laboratory data were used to generate moisture characteristic curves using the RETC computer code (van Genuchten et al., 1991). The documentation for the RETC code includes two methods for estimating the initial conditions for the RETC code (Rawls et al., 1982; Carsel and Parrish, 1988). Runs were made for each sample using both methods, which made a total of fifty 


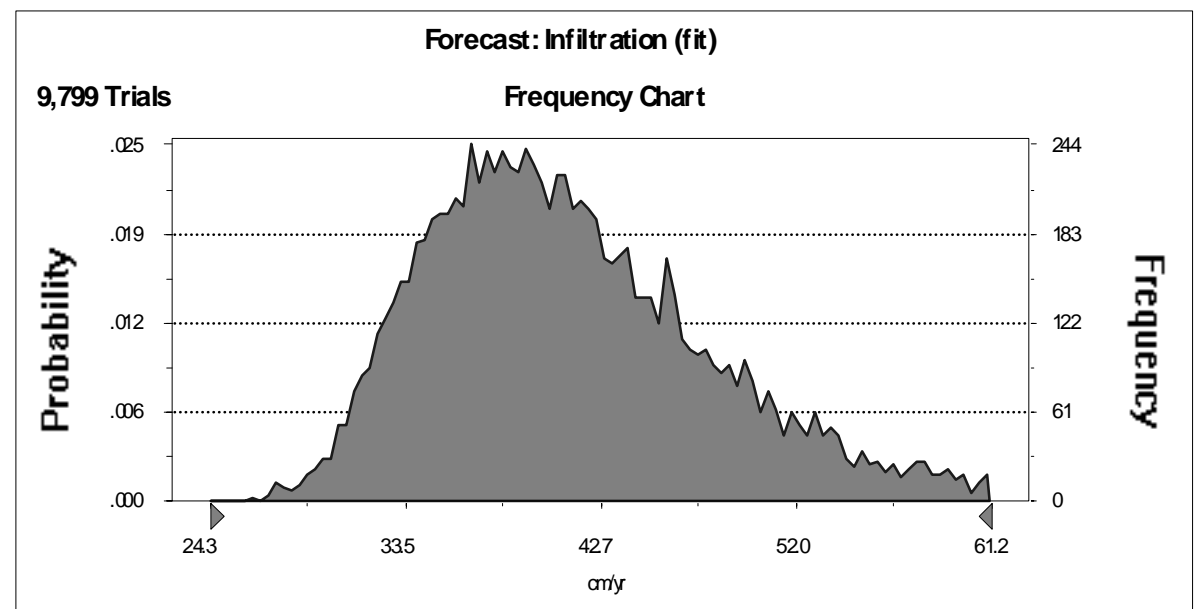

Figure 1. Probability density function of infiltration

Rev. 0 


\section{Infiltration $-10,000$ random samples in 100 bins}

Symbols for first 10 samples

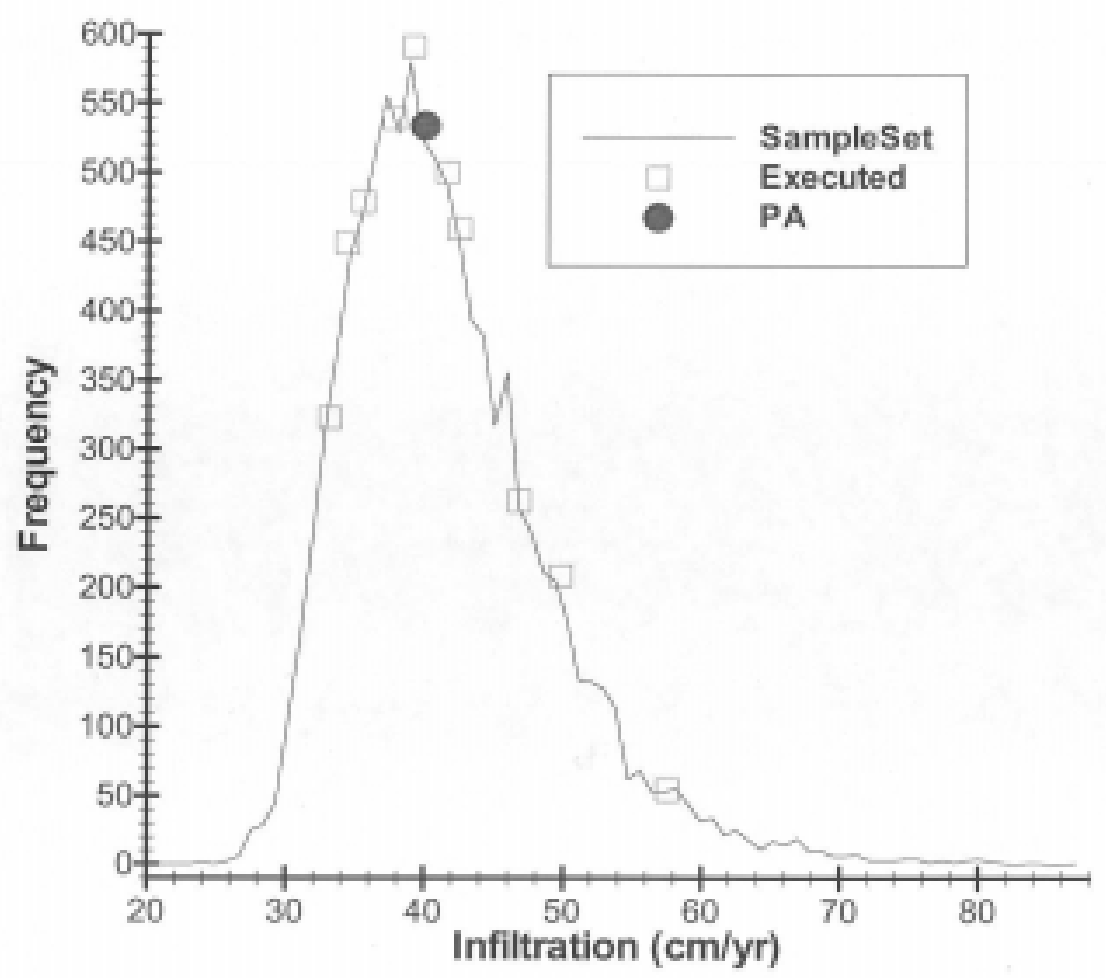

Figure 2. Infiltration - 10,000 random samples in 100 bins

Rev. 0 


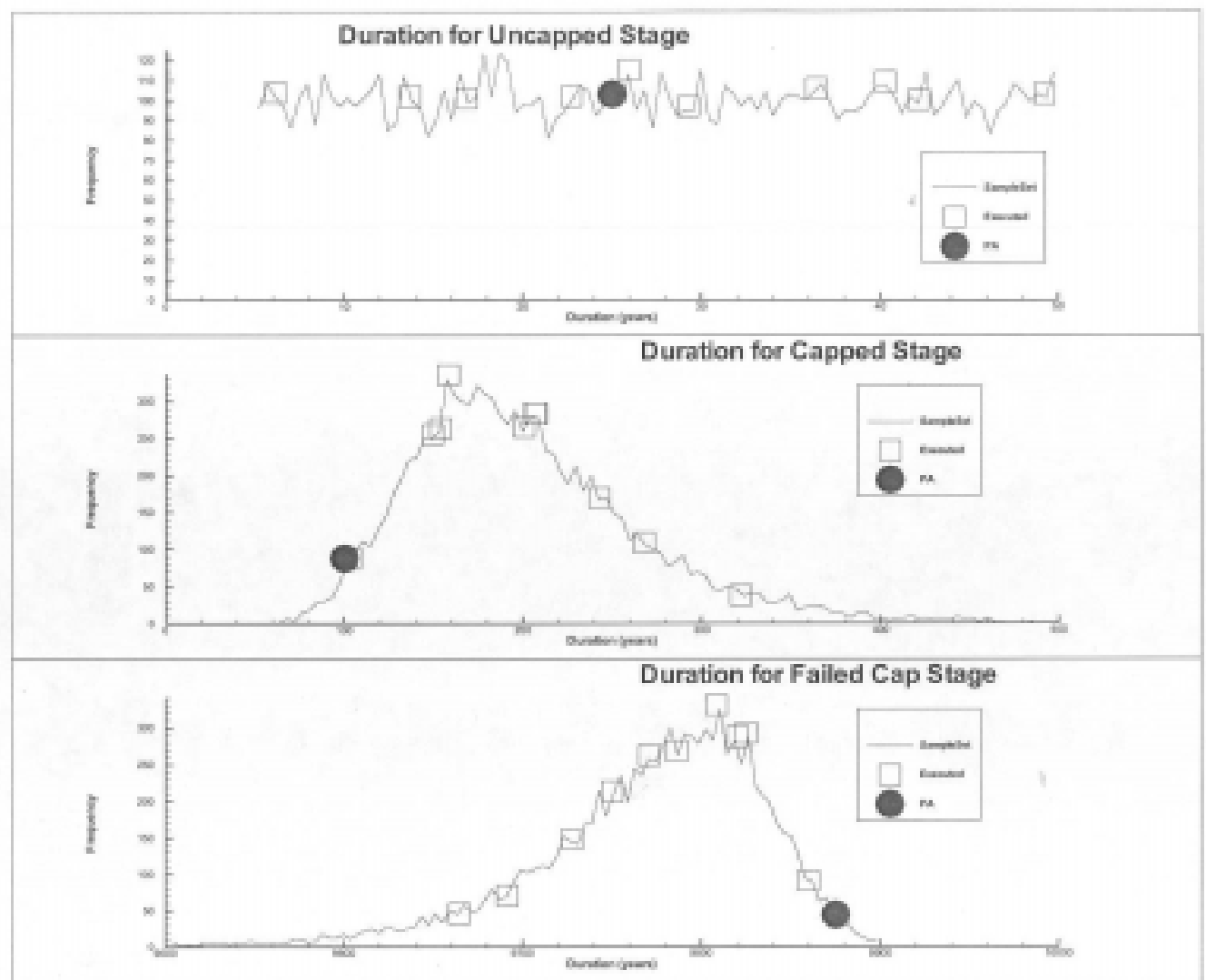

Figure 3. Probability distribution functions of cap performance times

Rev. 0 


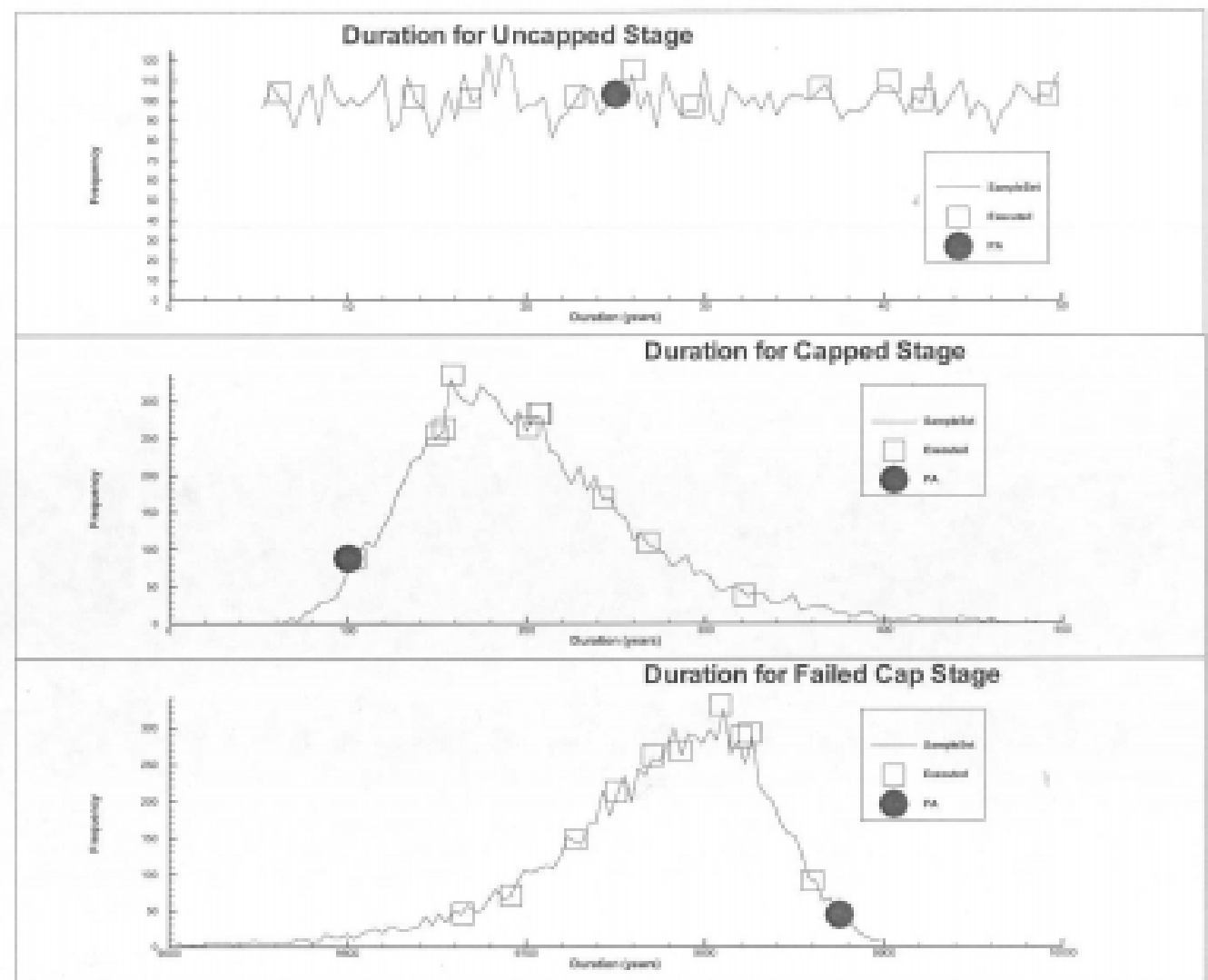

Figure 3. Probability distribution functions of cap performance times

Rev. 0 


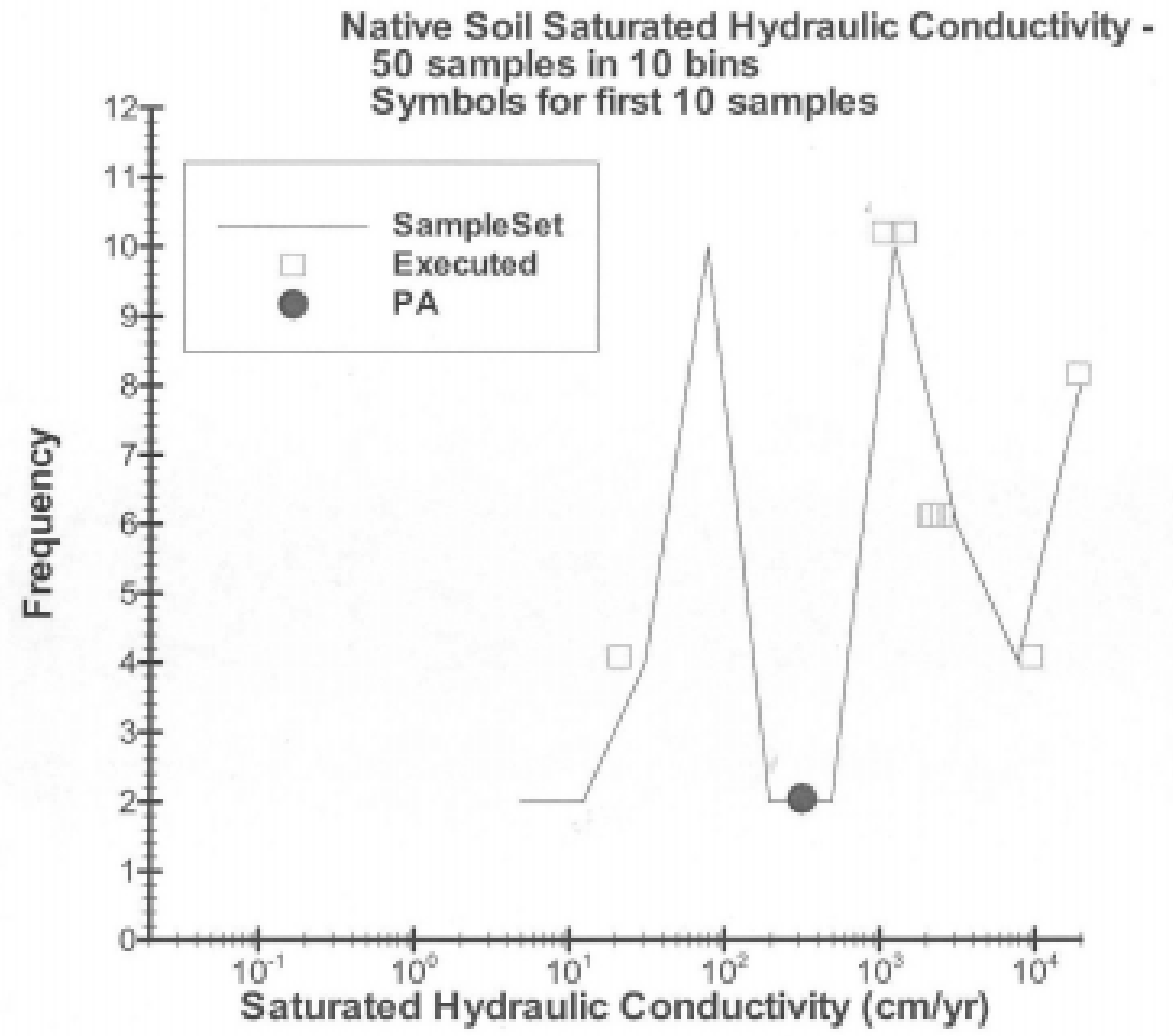

Figure 4. Probability distribution function of native soil saturated hydraulic conductivity 
moisture characteristic curves available for sampling. The sets of curves are shown in Figures 6 and 7.

\section{Saturated Zone Flow Model}

\section{Methodology}

A portion of the E-Area PA involves simulation of saturated groundwater flow beneath the General Separations Area (GSA) using FACT (Flach and others, 1999; Hamm and Aleman, 2000). The Darcy velocity field from the GSA flow model becomes input to subsequent transport simulations in the saturated zone using PORFLOW. Unique characteristics of the GSA flow model and overall PA analysis logistics motivate splitting uncertainty analysis for this portion of the PA from the remainder.

Inputs to the saturated flow model are strongly correlated in an implicit manner through model calibration to field data. Formal inputs to the groundwater flow model include a two-dimensional recharge field, and a three-dimensional hydraulic conductivity field. Other important "inputs" to the model are measured hydraulic heads from wells and stream baseflow estimates, which are used to condition the recharge and hydraulic conductivity fields through model calibration (i.e. inverse modeling). In fact, the model hydraulic conductivity field is primarily defined through model calibration to head, rather than hydraulic conductivity measurements. Model calibration is currently done through a time-consuming, manual, trial-and-error process, which severely limits the number of saturated flow realizations that can feasibly be generated.

To accommodate correlated inputs and manual model calibration, uncertainty in the groundwater flow model can be defined through the following process:

1) redefine model inputs to be the simpler set of

a) a global multiplier to recharge

b) a global multiplier to vertical conductivity in the Gordon confining unit

c) global multipliers to horizontal conductivity in aquifer zones and vertical conductivity in the tan clay confining zone,

d)

2) view input parameters 1a) and 1b) as independent, and sample each using three point midpoint LHS for a total of 9 output realizations $(3 \times 3)$,

3) manually adjust parameter 1c) as needed to maintain agreement between simulated and measured head values to the extent possible.

The output velocity fields can be randomly sampled with equal probability in the larger PA uncertainty analysis. Manual calibration in step 3) limits the number of realizations to a small number, chosen to be 9 in this instance. Based on engineering judgement, recharge and the log of the vertical conductivity are assumed to be normally distributed in step 2) in lieu of sufficient field data to empirically define a probability distribution. Note that $\mathrm{K}_{\mathrm{v}}$ is thus log-normally distributed.

Three-point mid-point LHS is illustrated in Figure 8 for a unit normal distribution $n(0,1)$ and three definitions of interval midpoint. All three definitions produce similar samples. The median value as midpoint is standard LHS, and produces the values $\mathrm{z}_{\mathrm{i}}=\{-0.967,0,+0.967\}$, where $z$ denotes normalized $\mathrm{z}$ score. A second possibility is the mean value of each interval, which yields $\mathrm{Z}_{\mathrm{i}}=\{-1.09,0,+1.09\}$. A third alternative is to choose midpoints such that the sample mean and 


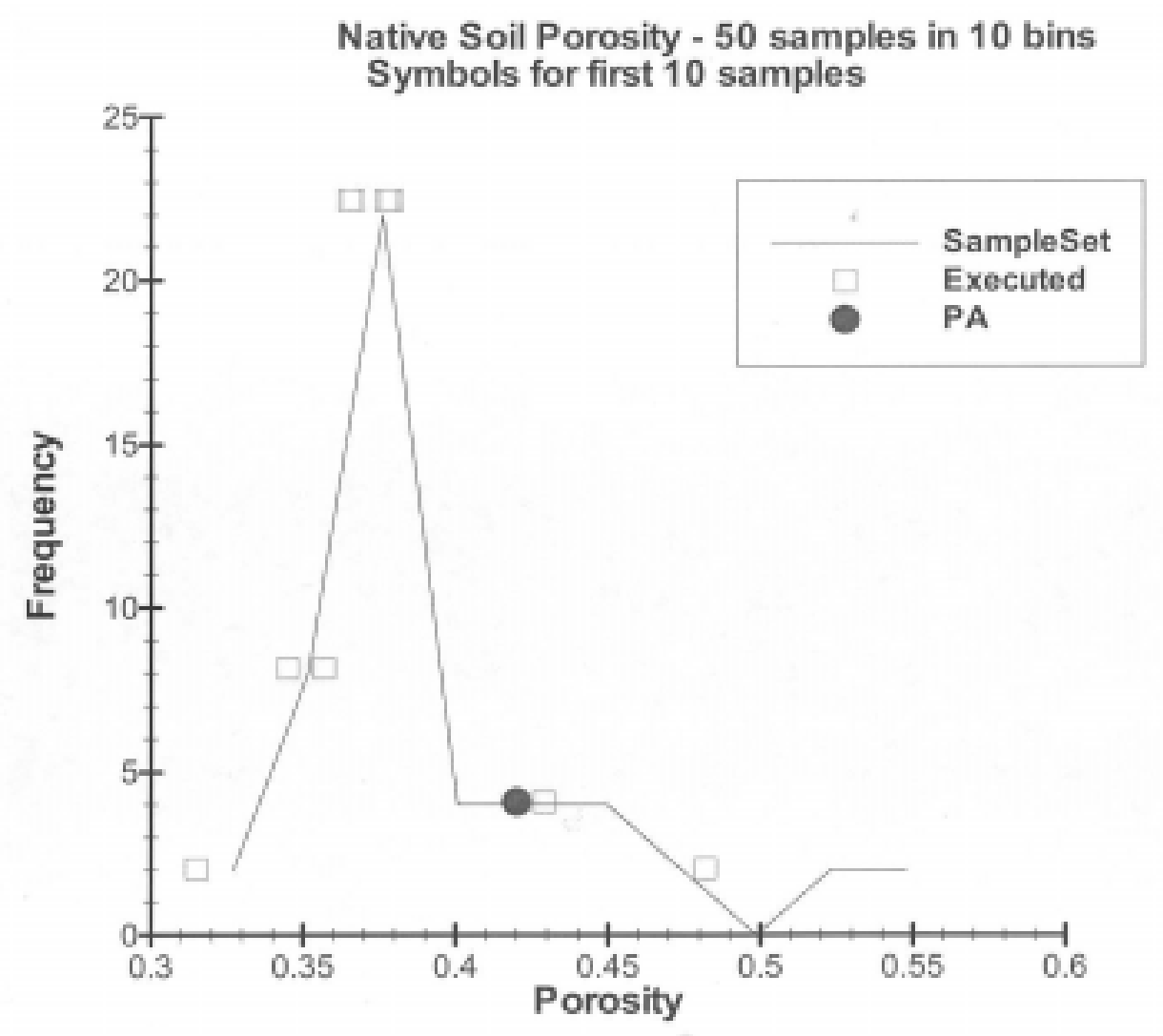

Figure 5. Probability distribution function of native soil porosity

Rev. 0 


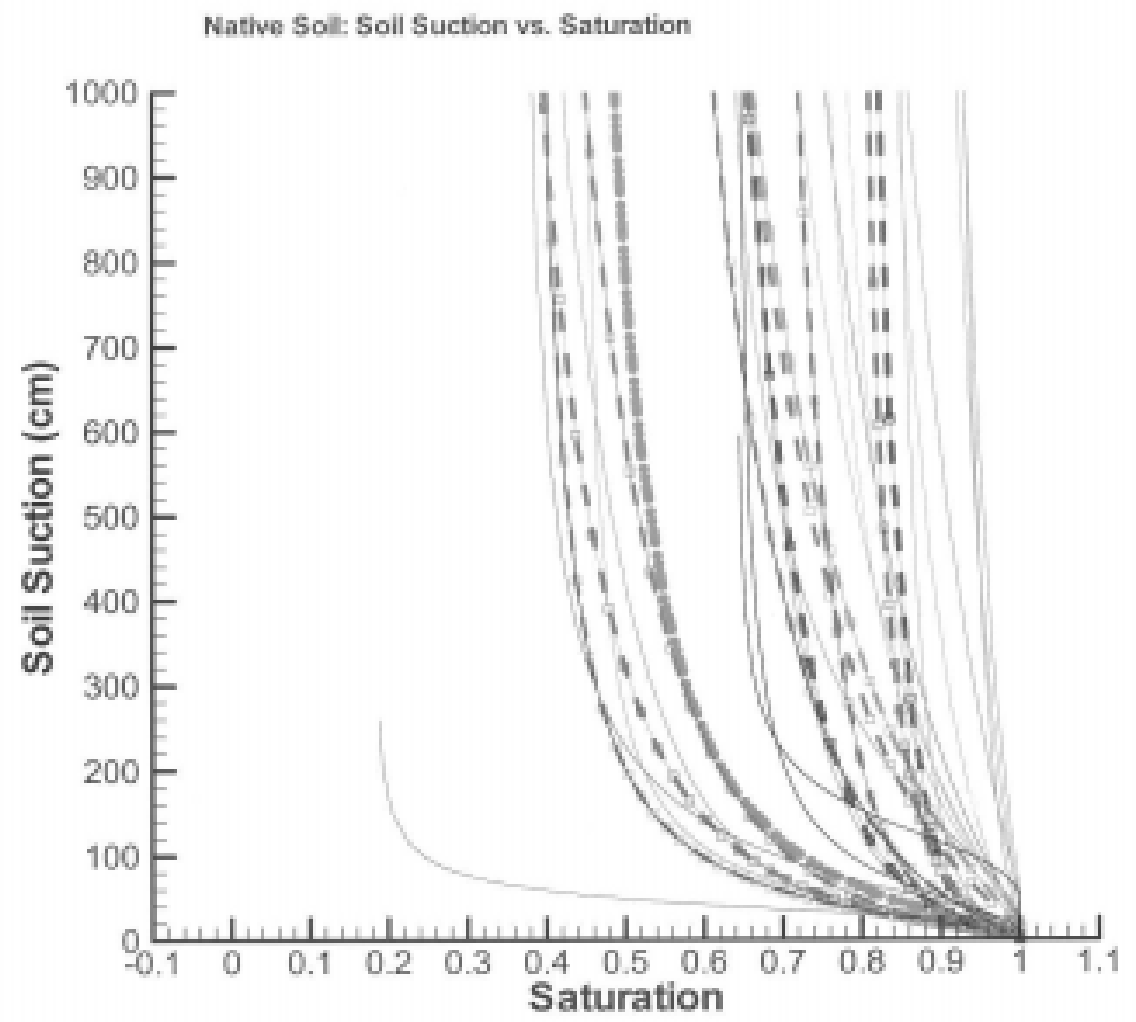

Figure 6. Soil suction versus saturation for native soil

Rev. 0 


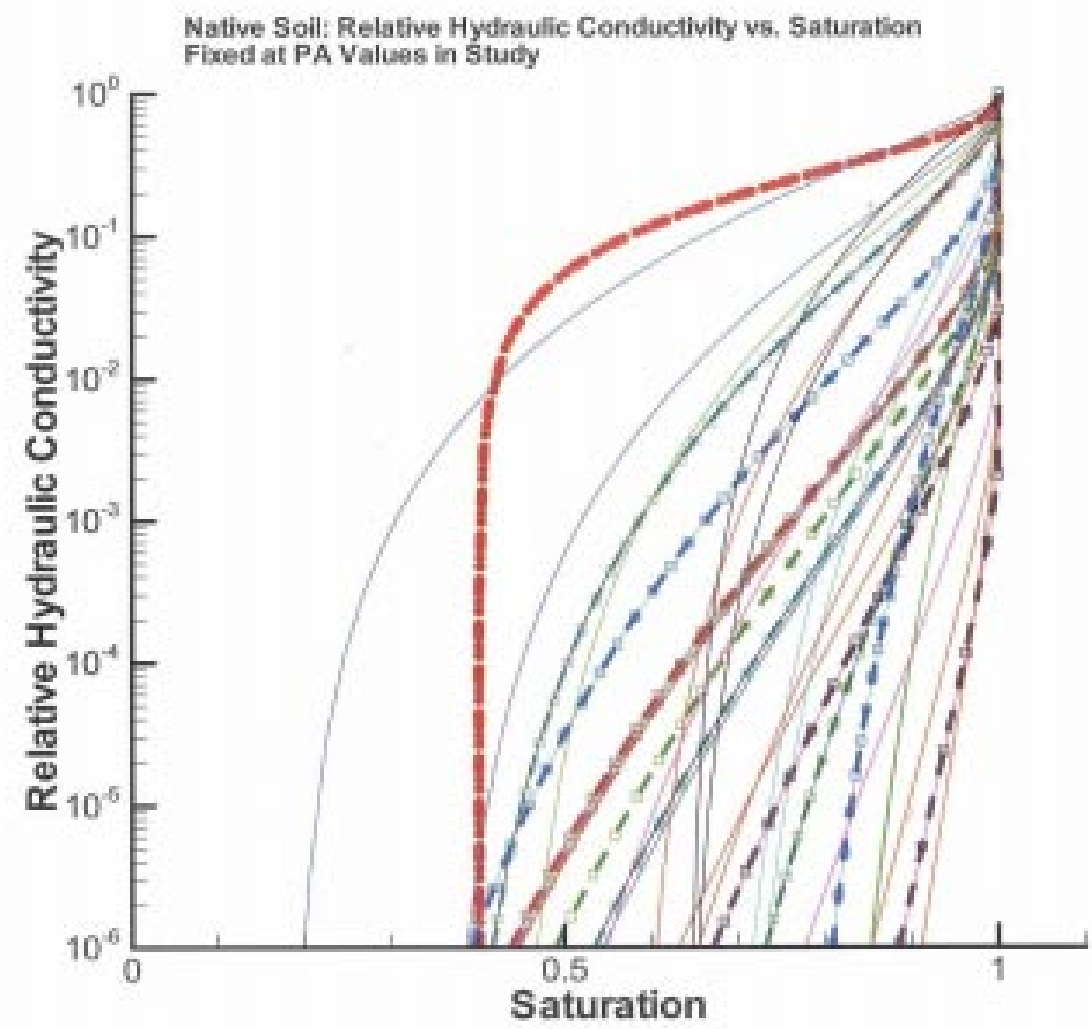

Figure 7. Relative hydraulic conductivity versus saturation for native soil

Rev. 0 


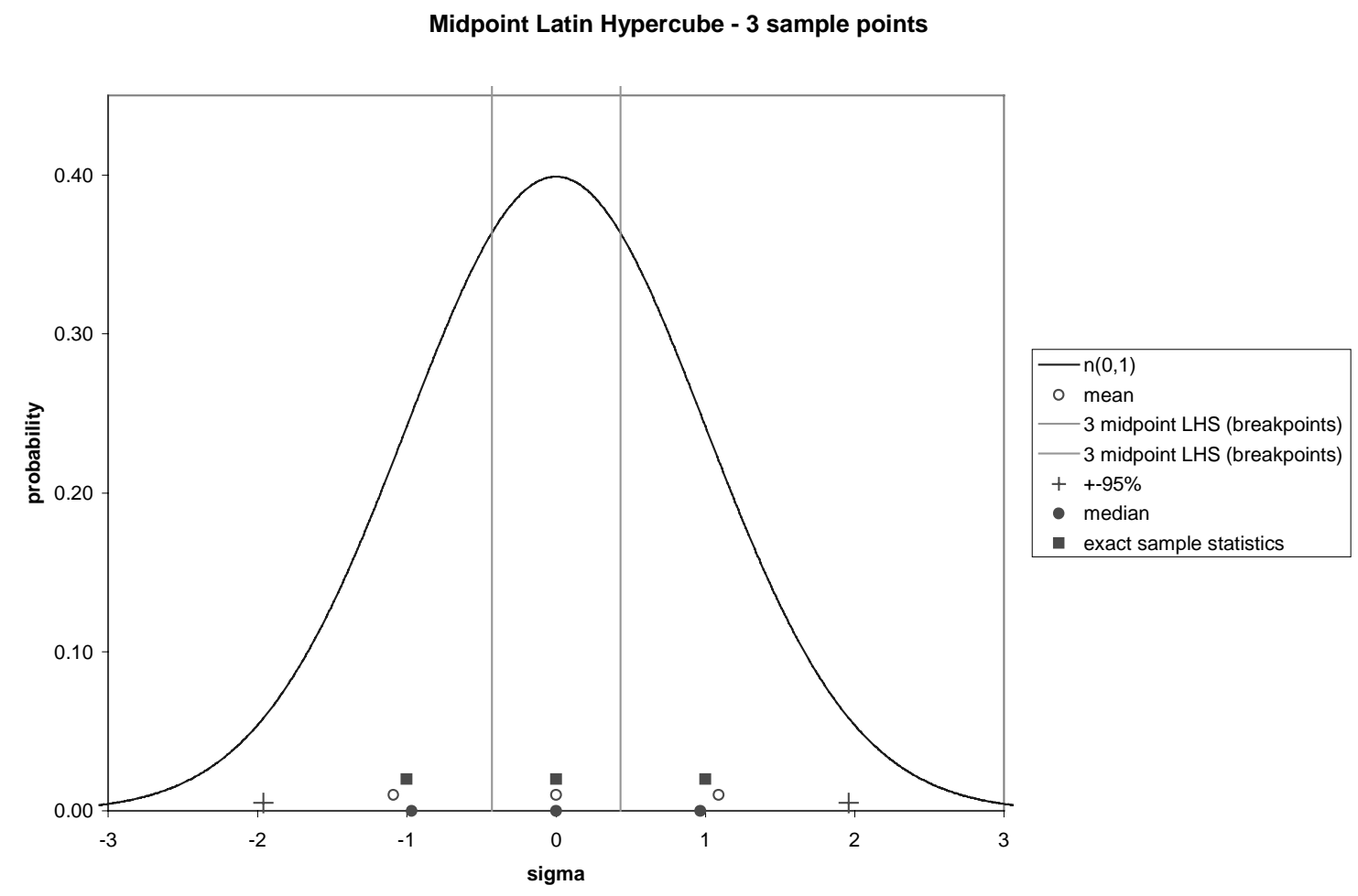

Figure 8 Illustration of three-point mid-point Latin Hypercube Sampling for a unit normal distribution and three definitions of the midpoint. 
variance exactly match the mean and variance of the underlying distribution, specifically, $\mathrm{z}_{\mathrm{i}}=\{-$ $1,0,+1\}$. The latter is chosen for the present study. For the more general normal distribution $n(\mu, \sigma)$, the 3 samples would be $x_{\mathrm{i}}=\{-\sigma, \mu,+\sigma)$.

\section{Uncertainty analysis for PA saturated flow model}

Following the method described above, nine Monte Carlo runs are needed as shown in Table 3. GCU denotes the Gordon confining unit. Each Monte Carlo run has been given an arbitrary but unique case number for future reference. As mentioned above, recharge and $\log 10\left(\mathrm{~K}_{\mathrm{v}}\right)$ are assumed to be normally distributed based on engineering judgement. The mean of each distribution is assumed to be the value used in the nominal PA run. Lacking sufficient field data to empirically define the standard deviations for recharge and GCU vertical conductivity, engineering judgement is also used to define these statistics. The specific approach chosen is summarized in Table 4 and summarized below.

First uncertainties in recharge and GCU $\mathrm{K}_{\mathrm{v}}$ are expressed in terms of $95 \%$ confidence intervals about the nominal PA input values. Recharge is judged to have a $\pm 5 \mathrm{in} / \mathrm{yr}$ uncertainty about the nominal PA value of $14.5 \mathrm{in} / \mathrm{yr}$, based on an analysis of past recharge studies by Flach and others (1999, section 2.4). Gordon confining unit (green clay) $\mathrm{K}_{\mathrm{v}}$ is judged to be uncertain to within 3 orders of magnitude about the nominal PA value of $10^{-5} \mathrm{ft} / \mathrm{d}$ (McDowell-Boyer et al., 2000), based on an assessment of field data and other calibrated models by Aadland and others (1995, cf. Plate 13), Flach and Harris (1999, p. 9) and Flach (1998, p. 4). For a normal distribution, the $95 \%$ confidence interval is $\pm 1.96 \sigma$, or practically $\pm 2 \sigma$, about the mean value. So, the standard deviation is easily computed from the specified uncertainty range. The corresponding LHS samples are 12, 14.5 and $17 \mathrm{in} / \mathrm{yr}$ for the global recharge, and $0.18 \times 10^{-5}, 1 \times 10^{-5}$ and $5.6 \times 10^{-5}$ for GCU $\mathrm{K}_{\mathrm{v}}$. Table 2 lists the corresponding multipliers to be applied to the recharge and $\log$ conductivity fields.

The model calibration results for the nine Monte Carlo cases in Table 3 using the standard deviations in Table 4 are summarized in Table 5. Note that all eight off-nominal realizations have hydraulic head residuals very close to that observed in the nominal run. Perturbations in stream baseflow are small compared to discrepancies between the nominal simulation and prior estimates. Therefore, all nine realizations are plausible and the associated Darcy velocity fields can be sampled with equal probability as intended. 
Table 3. Monte Carlo runs for PA saturated flow model.

\begin{tabular}{|rr|c|c|c|}
\hline & \multicolumn{3}{|c|}{ Recharge (in/yr) } \\
\hline \multirow{2}{*}{ GCU log10 Kv (ft/d) } & $-\sigma$, lower Kv & case 6 & case 2 & case 9 \\
\cline { 3 - 5 } & nominal & case 4 & case 1 & case 5 \\
\cline { 2 - 5 } & $+\sigma$, higher Kv & case 8 & case 3 & case 7 \\
\hline
\end{tabular}

Table 4. Input parameter uncertainty.

\begin{tabular}{|c|c|c|c|}
\hline \multicolumn{4}{|c|}{ Midpoint Latin Hypercube Sampling (LHS) using 3 samples } \\
\hline Recharge (in/yr) & Global & Local & $\mathrm{ft} / \mathrm{d}$ \\
\hline Nominal & 14.5 & 18 & 0.00411 \\
\hline $95 \%$ c.i. variability $(2 \sigma)$ & 5 & 6.2 & \\
\hline \%variability & $34 \%$ & $34 \%$ & \\
\hline$-95 \%$ confidence interval & 9.5 & 11.8 & \\
\hline +95\% confidence interval & 19.5 & 24.2 & \\
\hline -midpoint LHS point $(-\sigma)$ & 12 & 14.9 & 0.00340 \\
\hline+ midpoint LHS point $(+\sigma)$ & 17 & 21.1 & 0.00482 \\
\hline -midpoint LHS factor & 0.83 & 0.83 & \\
\hline +midpoint LHS factor & 1.17 & 1.17 & \\
\hline GCU $\log 10 \mathrm{Kv}(\mathrm{ft} / \mathrm{d})$ & $\log 10 \mathrm{Kv}$ & $\mathrm{Kv}$ & \\
\hline Nominal (new) & -5 & 1.0E-05 & \\
\hline $95 \%$ c.i. variability $(2 \sigma)$ & 1.5 & 32 (factor) & \\
\hline$\%$ variability & $30 \%$ & & \\
\hline$-95 \%$ confidence interval & -6.5 & $3.2 \mathrm{E}-07$ & \\
\hline +95\% confidence interval & -3.5 & 3.2E-04 & \\
\hline -midpoint LHS point $(-\sigma)$ & -5.75 & $1.8 \mathrm{E}-06$ & \\
\hline+ midpoint LHS point $(+\sigma)$ & -4.25 & 5.6E-05 & \\
\hline -midpoint LHS factor & 1.15 & 0.18 & \\
\hline +midpoint LHS factor & 0.85 & 5.62 & \\
\hline
\end{tabular}

Stream traces for each of the nine cases are shown in Figures 9 a-c. Each case has one-year time marks on each stream trace. Therefore, the more marks that are on a given line, the slower is the velocity along that trace. It can be seen that there is relatively little variation among the cases in pore velocity, meaning both speed and direction of water flow. 
Table 5 Calibration results for Monte Carlo runs

\begin{tabular}{|c|c|c|c|c|c|c|c|c|c|c|}
\hline & \multicolumn{2}{|l|}{ Values ... } & \multirow[b]{2}{*}{$-K v$} & \multirow[b]{2}{*}{$+\mathrm{Kv}$} & \multirow[b]{2}{*}{$-\mathbf{R}$} & \multirow[b]{2}{*}{$+R$} & \multirow[b]{2}{*}{$-K v,-R$} & \multirow[b]{2}{*}{$+K v,+R$} & \multirow[b]{2}{*}{$+K v,-R$} & \multirow[b]{2}{*}{$-K v,+R$} \\
\hline & & nominal & & & & & & & & \\
\hline Calibration measure & Target & Case 1 & Case 2 & Case 3 & Case 4 & Case 5 & Case 6 & Case 7 & Case 8 & Case 9 \\
\hline Global recharge & 15 & 14.5 & 14.5 & 14.5 & 12.1 & 17.0 & 12.1 & 17.0 & 12.1 & 17.0 \\
\hline Local recharge & no est. & 18.0 & 18.0 & 18.0 & 14.9 & 21.1 & 14.9 & 21.1 & 14.9 & 21.1 \\
\hline GAU Kh & no est. & 38 & 38 & 38 & 38 & 38 & 38 & 38 & 38 & 38 \\
\hline GCU $\log 10 \mathrm{Kv}$ & no est. & .5 .0 & -5.75 & -4.25 & -50 & .5 .0 & -5.75 & -4.25 & -4.25 & -5.75 \\
\hline LAZ Kh & no est. & 9.3 & 9.3 & 8.1 & 7.4 & 10.5 & 7.7 & 9.1 & 6.5 & 10.8 \\
\hline TCCZ log10 Kv & no est. & -2.2 & -2.2 & -2.2 & -2.2 & -2.1 & -2.2 & -2.1 & -2.2 & -2.1 \\
\hline UAZ Kh - below WT & no est. & 9.6 & 9.9 & 8.5 & 7.8 & 12.0 & 7.8 & 11.7 & 6.8 & 12.3 \\
\hline $\begin{array}{r}\text { All wells } \\
\end{array}$ & varies & & & & & & & & & \\
\hline GAU head & varies & & & & & & & & & \\
\hline LAZ head & varies & & & & & & & & & \\
\hline UAZ head & varies & & & & & & & & & \\
\hline UTR baseflow & 18.2 & 9.7 & 9.8 & 9.6 & 8.7 & 10.7 & 8.8 & 10.6 & 8.6 & 10.7 \\
\hline Fourmile baseflow & 2.6 & 3.6 & 3.7 & 3.2 & 3.1 & 4.2 & 3.1 & 3.9 & 2.7 & 4.3 \\
\hline McQueen Branch baseflow & 1.5 & 4.7 & 4.8 & 4.5 & 4.4 & 5.1 & 4.4 & 4.9 & 4.2 & 5.1 \\
\hline \multirow[t]{2}{*}{ Crouch Branch baseflow } & 1.8 & 1.6 & 1.7 & 1.5 & 1.4 & 1.9 & 1.4 & 1.8 & 1.2 & 1.9 \\
\hline & \multirow{2}{*}{\multicolumn{2}{|c|}{ Differences }} & & & & & & & & \\
\hline & & & & & & & & & & \\
\hline & & nominal & $-K v$ & $+\mathrm{Kv}$ & $-\mathbf{R}$ & $+\mathbf{R}$ & $-K v,-R$ & $+\mathrm{Kv},+\mathrm{R}$ & $+K v,-R$ & $-K v,+R$ \\
\hline Calibration measure & & Case 1 & Case 2 & Case 3 & Case 4 & Case 5 & Case 6 & Case 7 & Case 8 & Case 9 \\
\hline Global recharge & & -0.5 & -0.5 & -0.5 & -2.9 & 2 & -2.9 & 2 & -2.9 & 2 \\
\hline Local recharge & & - & 0 & 0 & -3.1 & 3.1 & -3.1 & 3.1 & -3.1 & 3.1 \\
\hline GAU Kh & & - & 0 & 0 & 0 & 0 & 0 & 0 & 0 & 0 \\
\hline GCU $\log 10 \mathrm{Kv}$ & & - & -0.75 & 0.75 & 0 & 0 & -0.75 & 0.75 & 0.75 & -0.75 \\
\hline LAZ Kh & & - & 0 & -1.2 & -1.9 & 1.2 & -1.6 & -0.2 & -2.8 & 1.5 \\
\hline TCCZ log10 Kv & & - & 0 & 0 & 0 & 0.1 & 0 & 0.1 & 0 & 0.1 \\
\hline UAZ Kh - below WT & & - & 0.3 & -1.1 & -1.8 & 2.4 & -1.8 & 2.1 & -2.8 & 2.7 \\
\hline $\begin{array}{l}\text { All wells } \\
\end{array}$ & rms & 3.30 & 3.33 & 3.18 & 3.35 & 3.31 & 3.39 & 3.18 & 3.23 & 3.35 \\
\hline GAU head & rms & 2.48 & 2.72 & 1.67 & 2.53 & 2.44 & 2.76 & 1.65 & 1.69 & 2.67 \\
\hline LAZ head & rms & 4.80 & 4.83 & 4.66 & 4.89 & 4.76 & 4.94 & 4.57 & 4.70 & 4.78 \\
\hline UAZ head & rms & 2.59 & 2.58 & 2.58 & 2.60 & 2.65 & 2.60 & 2.65 & 2.64 & 2.66 \\
\hline GAU head & median & -1.20 & -1.40 & 0.20 & -1.20 & -1.20 & -1.40 & 0.20 & 0.10 & -1.40 \\
\hline LAZ head & median & -0.40 & -0.15 & 0.00 & 0.30 & 0.00 & 0.20 & -0.05 & 0.20 & -0.20 \\
\hline UAZ head & median & 0.00 & 0.10 & 0.30 & 0.00 & 0.30 & -0.10 & 0.30 & -0.20 & 0.10 \\
\hline UTR baseflow & & -8.5 & -8.4 & -8.6 & -9.5 & -7.5 & -9.4 & -7.6 & -9.6 & -7.5 \\
\hline Fourmile baseflow & & 1 & 1.1 & 0.6 & 0.5 & 1.6 & 0.5 & 1.3 & 0.1 & 1.7 \\
\hline McQueen Branch baseflow & & 3.2 & 3.3 & 3 & 2.9 & 3.6 & 2.9 & 3.4 & 2.7 & 3.6 \\
\hline Crouch Branch baseflow & & -0.2 & -0.1 & -0.3 & -0.4 & 0.1 & -0.4 & 0 & -0.6 & 0.1 \\
\hline
\end{tabular}




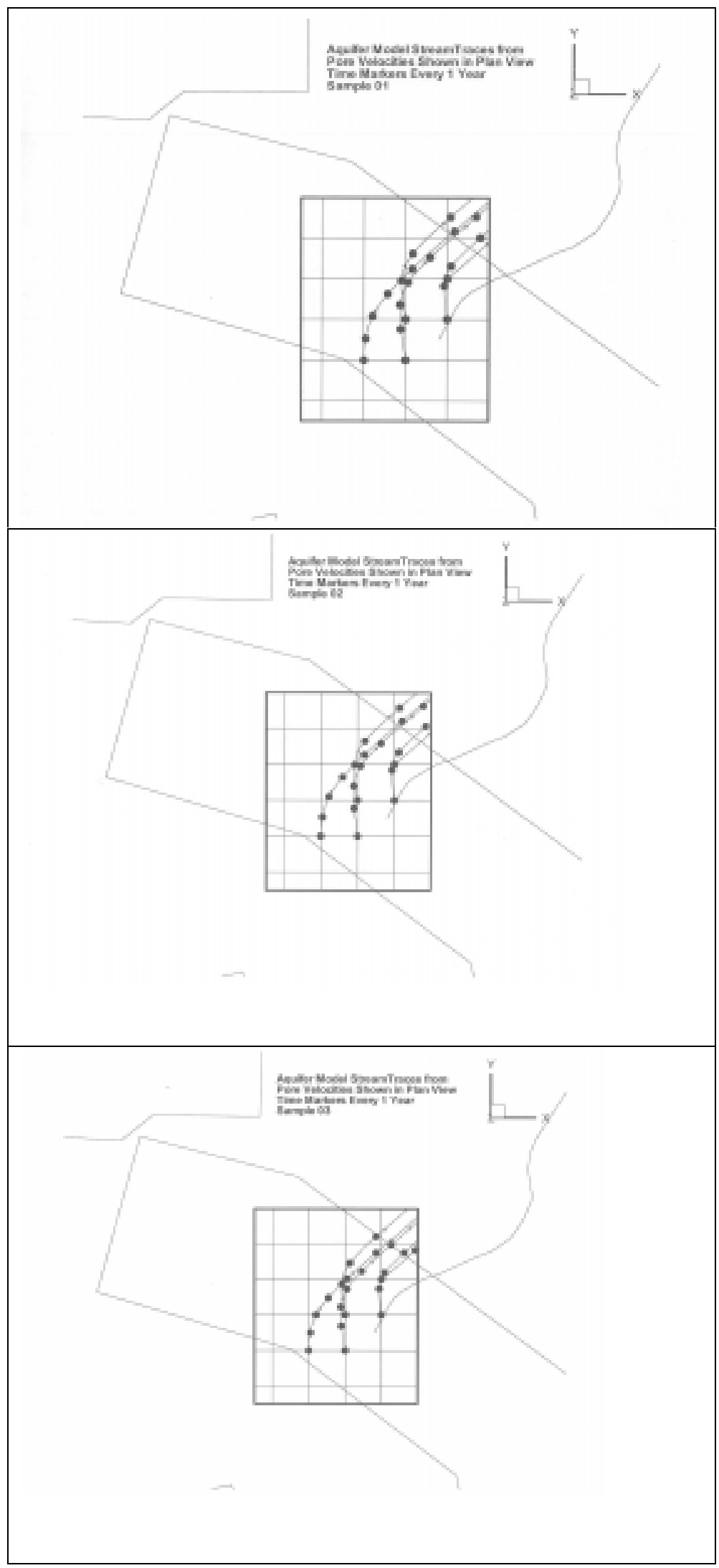

Figure 9a. Aquifer stream traces

Rev. 0 


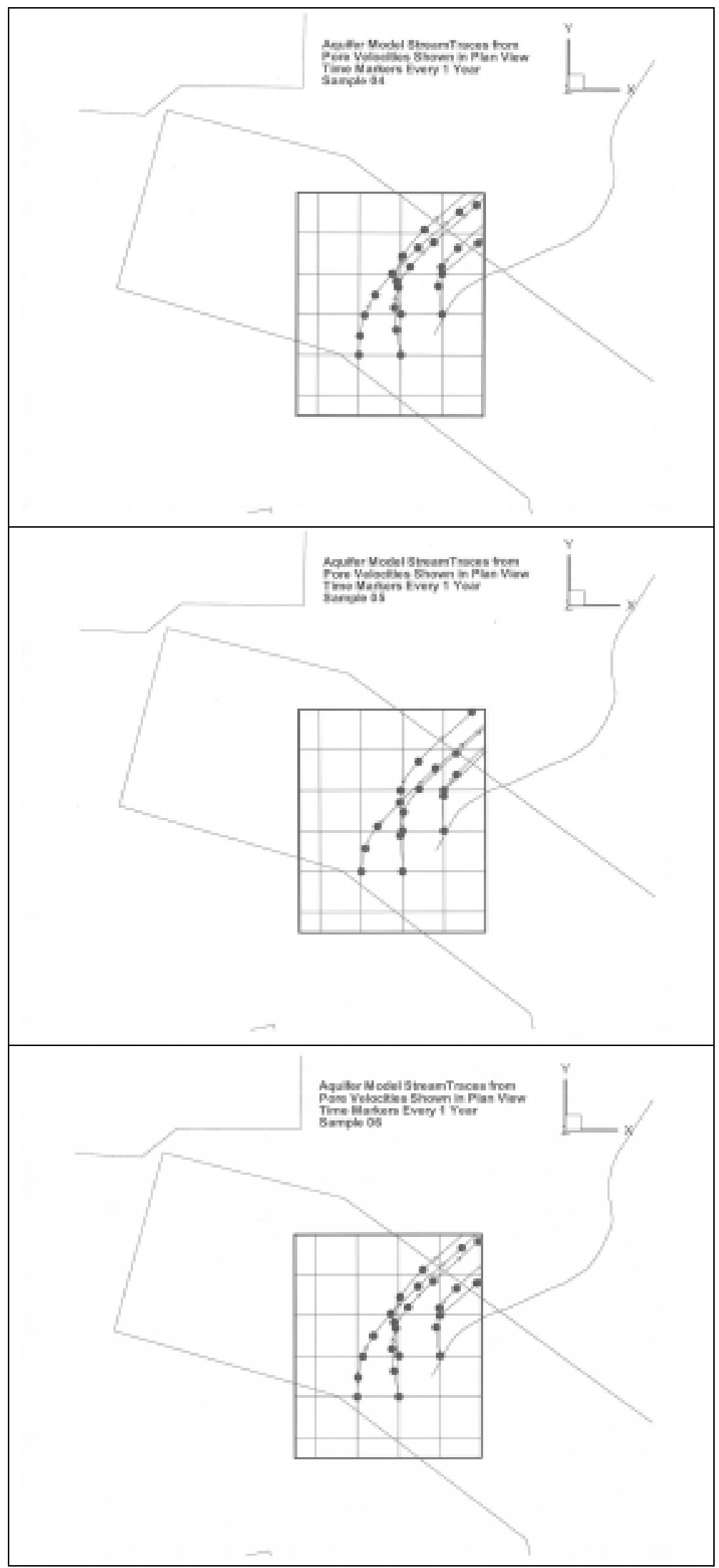

Figure 9b. Aquifer stream traces

Rev. 0 


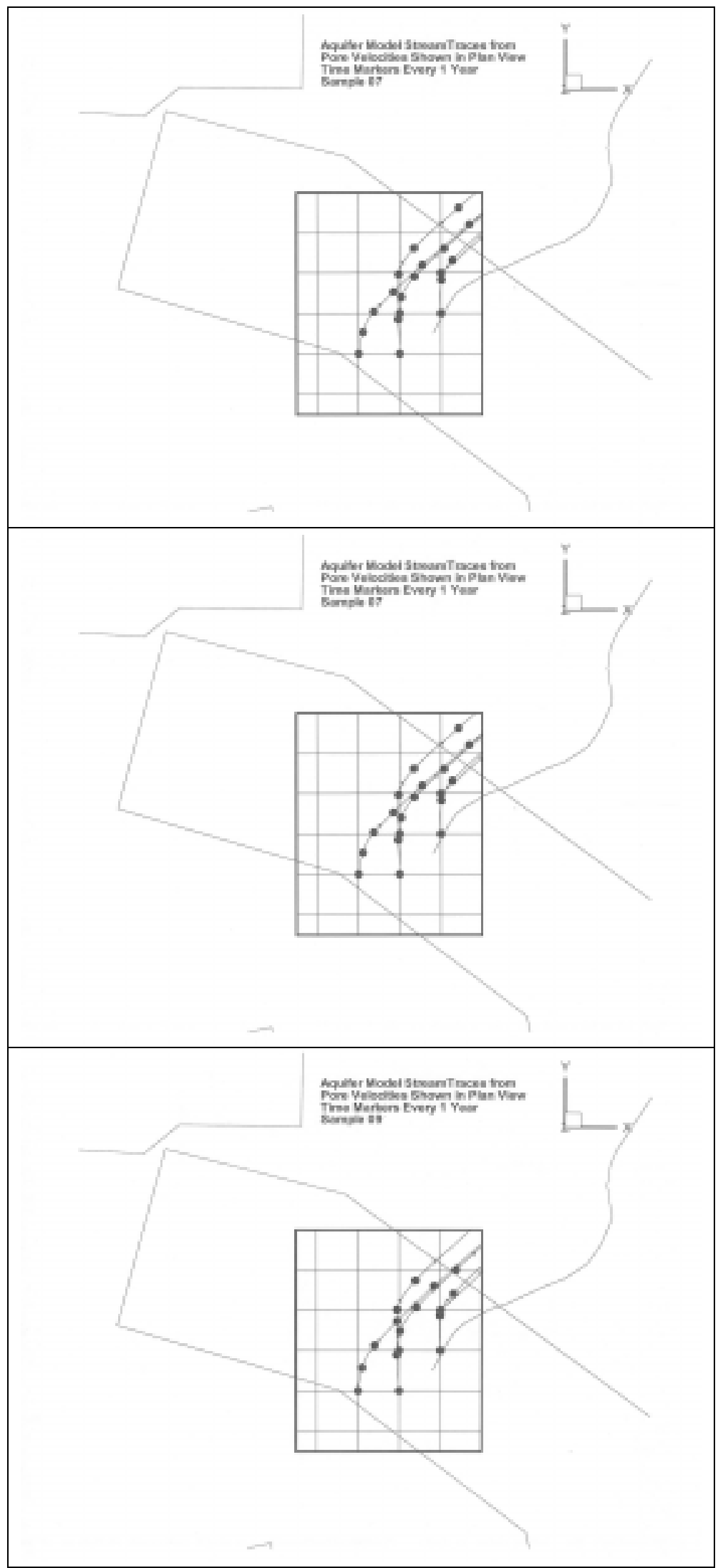

Figure 9c. Aquifer stream traces

Kev. $u$ 


\section{Transport Models}

\section{Partition Coefficients}

Probability density functions were developed for partition coefficients $\left(\mathrm{K}_{d} \mathrm{~s}\right)$ for sand and clay for iodine, and strontium.

It was assumed that the sand and clay $\mathrm{K}_{d} \mathrm{~s}$ are distributed lognormally based on the data from Sheppard and Thibault (1990) listed in Table 6.

Table 6. Distribution Parameters for Sampled Sand and Clay $\mathbf{K}_{d} \mathbf{S}$

\begin{tabular}{ccccc}
\hline \hline Constituent & \multicolumn{2}{c}{ Mean of $\ln \left(\mathrm{K}_{d}\right)(\mathrm{ml} / \mathrm{g})$} & \multicolumn{2}{c}{ Standard Deviation of $\ln \left(\mathrm{K}_{d}\right)(\mathrm{ml} / \mathrm{g})$} \\
& $\underline{\text { Sand }}$ & $\underline{\text { Clay }}$ & $\underline{\text { Sand }}$ & $\underline{\text { Clay }}$ \\
$\mathrm{I}$ & 0.04 & 0.5 & 2.2 & 1.5 \\
$\mathrm{Sr}$ & 2.6 & 4.7 & 1.6 & 2 \\
\hline \hline
\end{tabular}

The values in Table 6 are used to develop a normal distribution in the statistical analysis software Crystal Ball ${ }^{\circledR} 2000$ (Decisioneering 2000) with a pdf of:

$$
f(x)=\frac{1}{\sqrt{2 \pi} s} e^{-\left(x-m^{\prime}\right)^{2} / 2 s^{2}} \quad \text { for }-\infty<x<\infty
$$

where $m^{\prime}$ and $s^{\prime}$ are the mean and standard deviation of the distributions, respectively, defined in Table 6 by their natural logs thereby yielding a lognormal distribution. These distributions are sampled 10,000 times using the Latin Hypercube sampling methodology with each realization transformed to a $\mathrm{K}_{d}$ value by exponentiation, yielding a lognormal distribution of sand and clay $\mathrm{K}_{d} \mathrm{~s}$ with a pdf of:

$$
f(x)=\frac{1}{x \sqrt{2 \pi} s} e^{-(\ln (x)-m)^{2} / 2 s^{2}} \quad \text { for }-\infty<x<\infty
$$

(Decisioneering 2000) where $m$ and $s$ are the mean and standard deviation of the distributions, respectively, listed in Table 7 and plotted in Figure 10

Table 7. Distribution Parameters for Resultant Sand and Clay $\mathbf{K}_{d} \mathbf{s}$

\begin{tabular}{ccccc}
\hline \hline Constituent & \multicolumn{2}{c}{$\mathrm{K}_{d}$ Mean } & $(\mathrm{ml} / \mathrm{g})$ & \multicolumn{2}{c}{$\mathrm{K}_{d}$ Standard Deviation $(\mathrm{ml} / \mathrm{g})$} \\
& $\underline{\text { Sand }}$ & $\underline{\text { Clay }}$ & $\underline{\text { Sand }}$ & $\underline{6}$ \\
$\mathrm{I}$ & 6 & 4 & 16 & 1,151 \\
$\mathrm{Sr}$ & 35 & 504 & 58 & 58 \\
\hline \hline
\end{tabular}



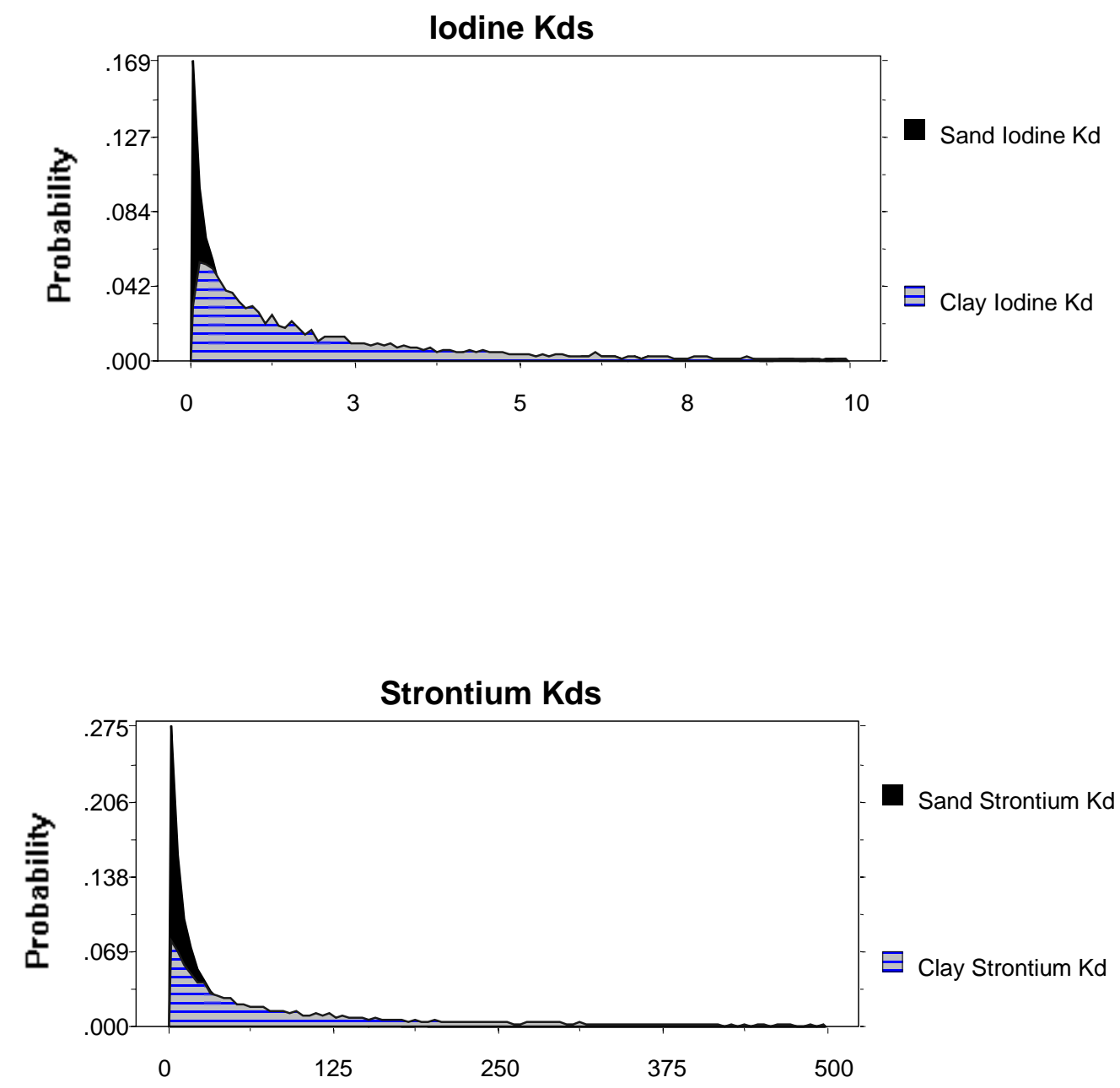

Figure 10. Probability distribution functions for iodine and strontium $K_{d} S$

Rev. 0 
The 10,000 values were then sorted and grouped into bins for sampling. The probability density functions for native soil $\mathrm{K}_{\mathrm{d}}{ }^{129} \mathrm{I}$ and ${ }^{90} \mathrm{Sr}$ for in the unsaturated runs are shown in Figures 11 and 12 , respectively. The probability density functions for $\mathrm{K}_{\mathrm{d}}$ values for sand and clay in the aquifer are shown in Figures 13-16.

\section{Particle Density}

Native soil particle density was a parameter measured for the samples from the Vadose Zone Monitoring Program (Holmes-Burns, 2001). The probability density function of the data and the values resulting from the sampling of the distribution are shown in Figure 17.

\section{RESULTS}

\section{Flux to the Water Table}

A key intermediate result of the PA calculations is the flux to the water table, which is the output from the unsaturated zone model. Cumulative probability plots of the peak flux and the time at which it occurs for each realization for both ${ }^{129} \mathrm{I}$ and ${ }^{90} \mathrm{Sr}$ are shown in Figures 18 through 21.

\section{Concentration at the 100-meter well}

The results of each of the realizations for ${ }^{129} \mathrm{I}$ and ${ }^{90} \mathrm{Sr}$ in terms of concentration at the 100-meter well versus time are shown in Figures 22 and 23, respectively.

Most of the curves for both radionuclides show a "double hump" nature. This is due to the fact that there is an initial uncapped period during which radionuclides are released relatively quickly, a capped period, where release is slowed, then a long period where the cap is assumed to have failed and thus offers no barrier to infiltrating water.

Figures 24 and 25 show the cumulative probability for the peak ${ }^{129} \mathrm{I}$ and ${ }^{90} \mathrm{Sr}$ concentrations at the 100 meter well, respectively. Figures 26 and 27 shown the cumulative probability for the time of occurrence for the peak concentrations.

\section{CONCLUSIONS}

This work was undertaken as a first step in assessing the methodology for incorporating probabilistic uncertainty analysis techniques into the performance assessment process at SRS. Due to the very limited scope of this investigation, this work should not be considered an actual probabilistic uncertainty analysis. A full probabilistic uncertainty analysis would involve everal thousand realizations on a much larger set of input parameters, and would include consideration of model uncertainty as well.

The conclusions of this work are:

1. The specific modeling process used at SRS is not readily adaptable to an automated process of making a large number of model runs.

The modeling process used for the SRS PA breaks the problem into four parts, unsaturated zone flow, unsaturated zone transport, saturated zone flow and saturated zone transport. The unsaturated zone flow field is set up and a number of test runs are usually needed to achieve the required convergence and mass balance. The saturated zone flow field is generated using a 


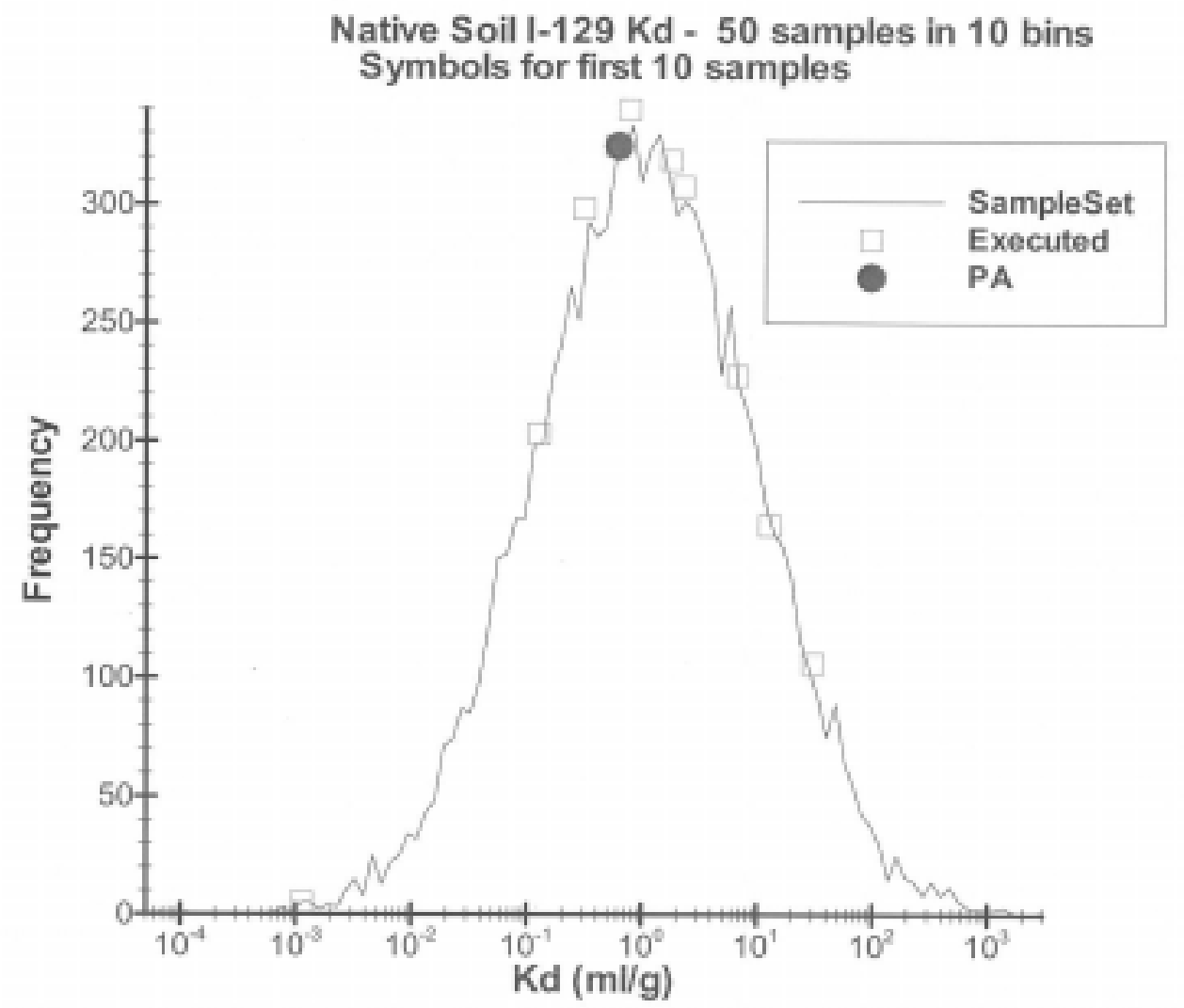

Figure 11. Probability distribution function of native soil I-129 $\mathbf{K}_{\mathbf{d}}$ 


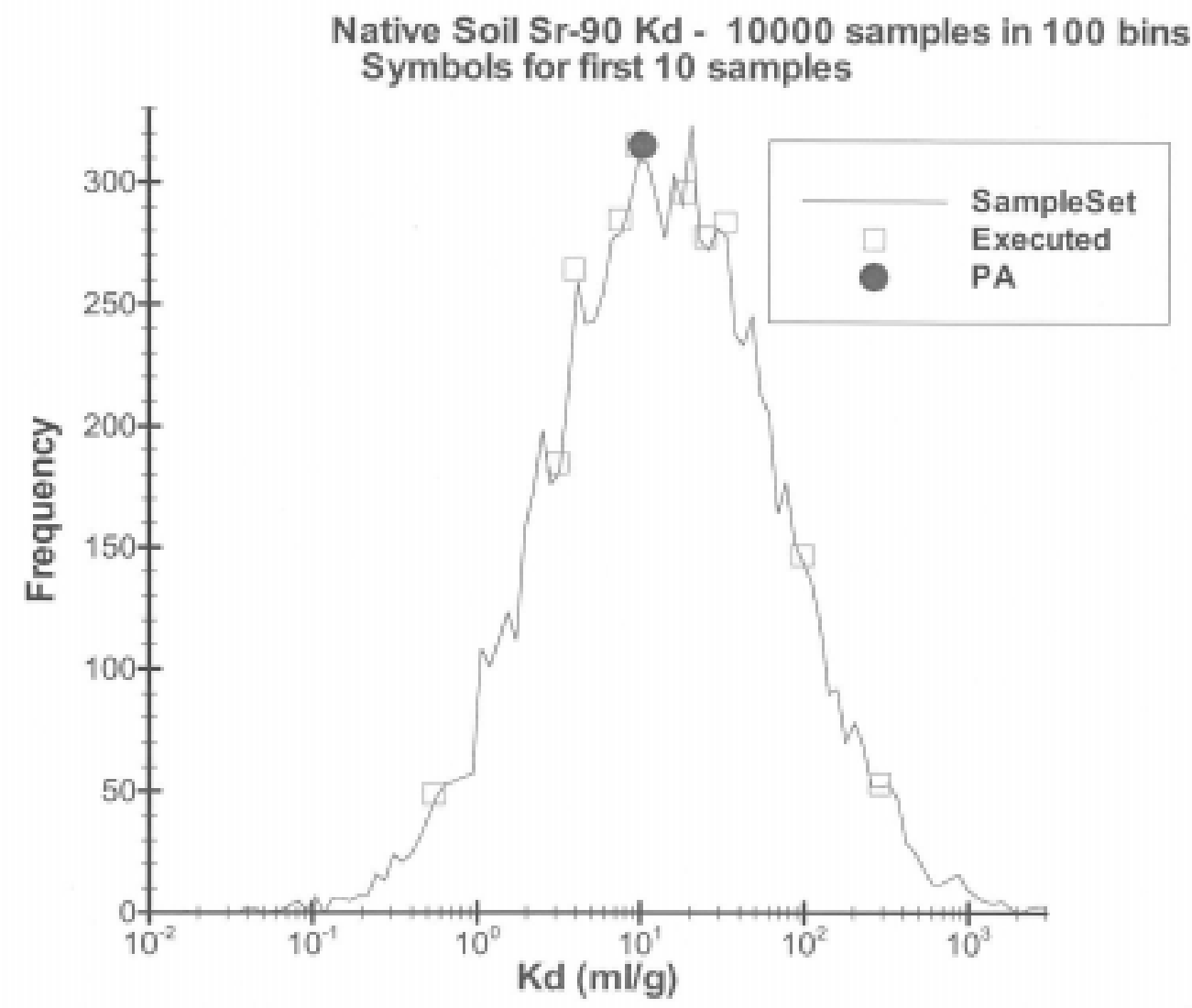

Figure 12. Probability distribution function of native soil Sr-90 $\mathbf{K}_{d}$

Rev. 0 


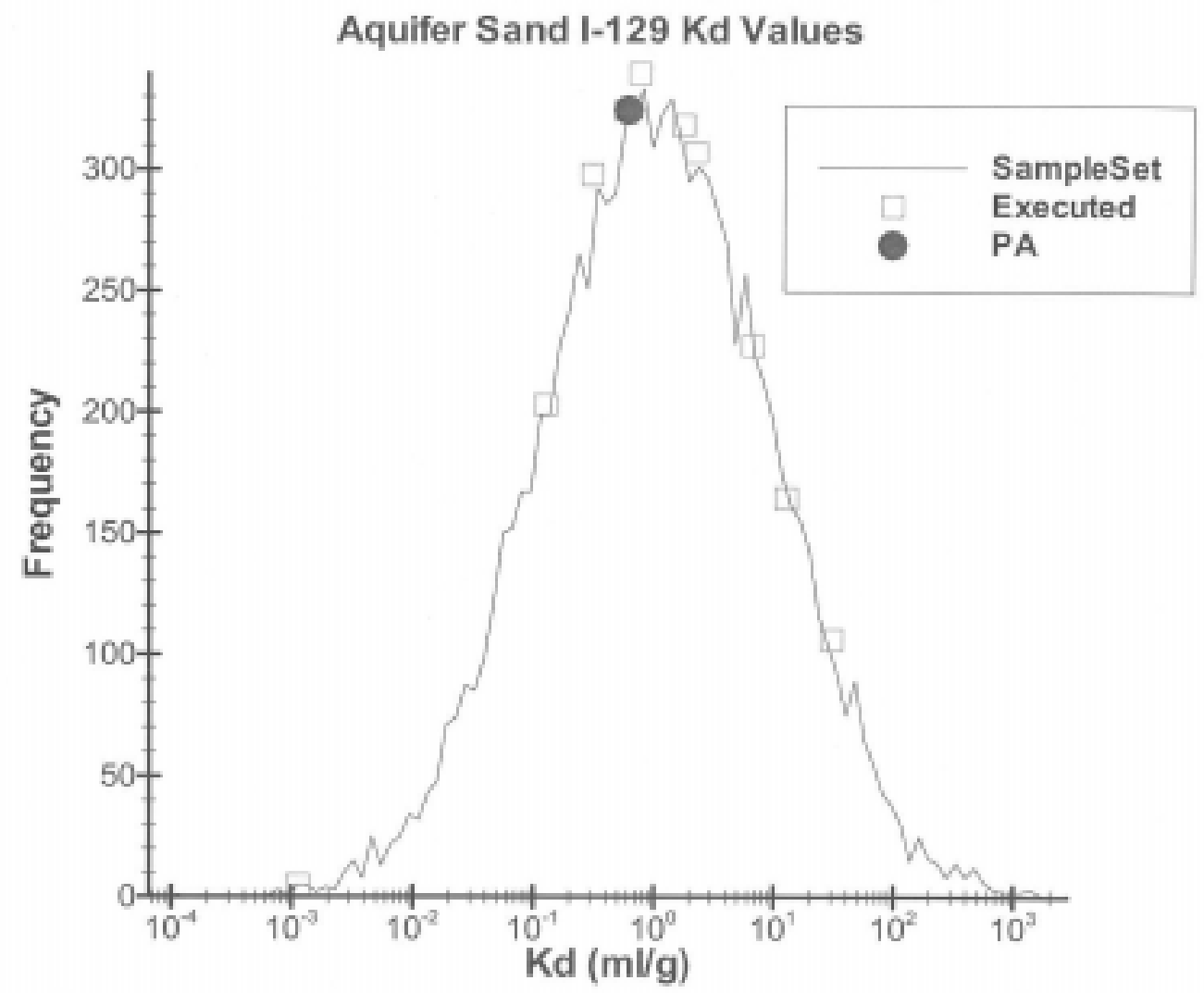

Figure 13. Probability distribution function of aquifer sand I-129 $K_{d}$ 


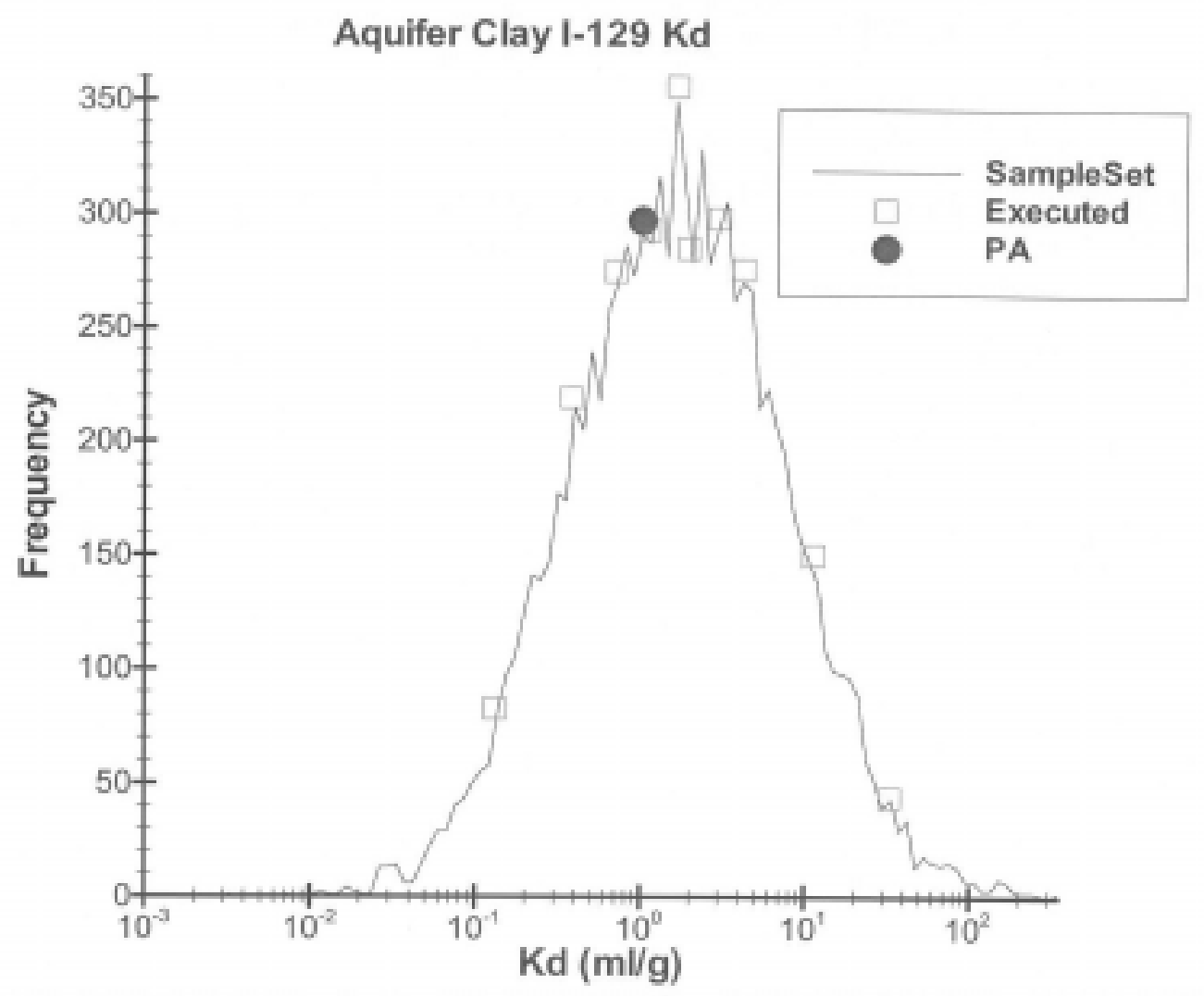

Figure 14. Probability distribution function of aquifer clay $I-129 K_{d}$

Rev. 0 


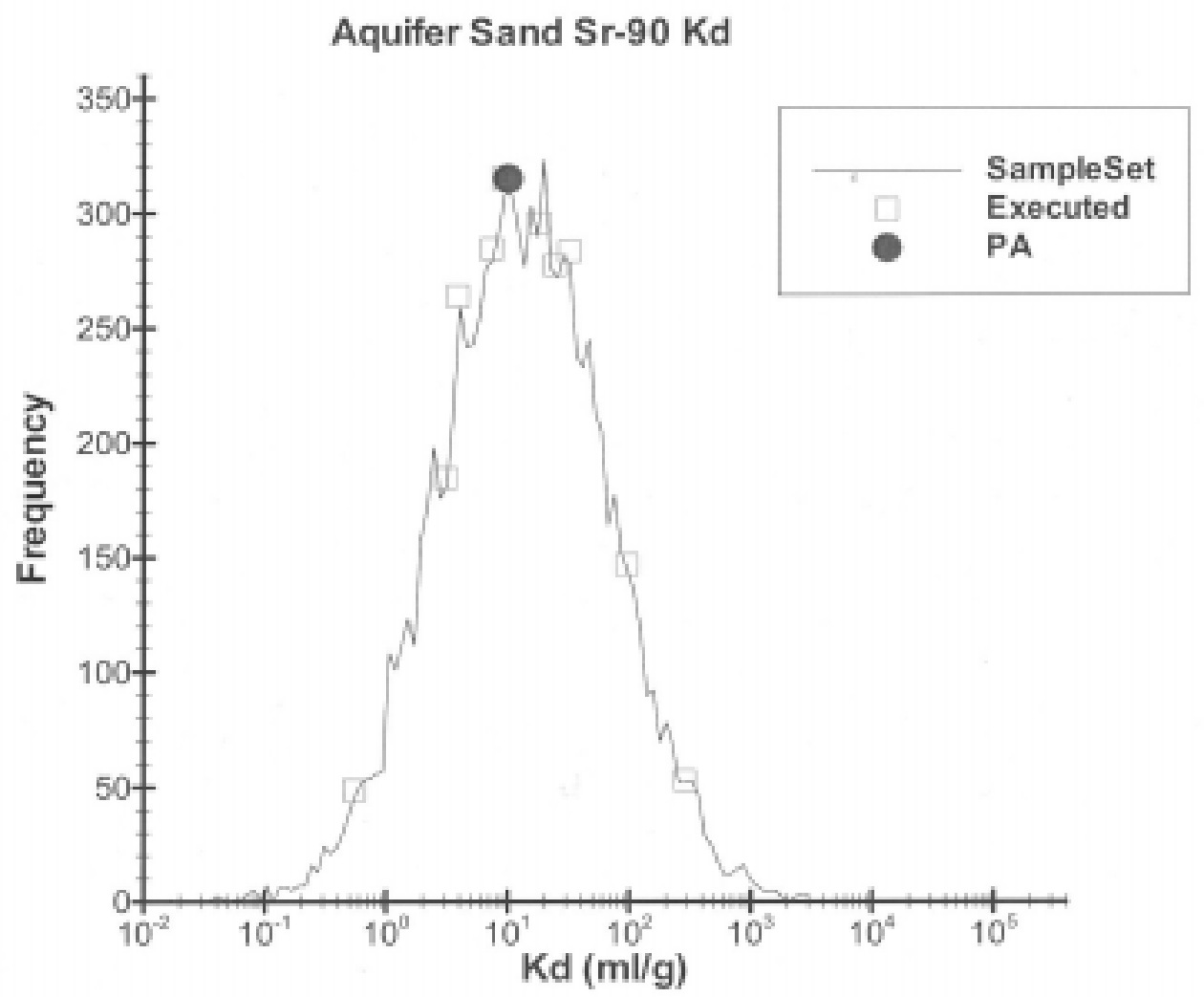

Figure 15. Probability distribution function of aquifer sand $\mathrm{Sr}-90 \mathrm{~K}_{d}$

Rev. 0 


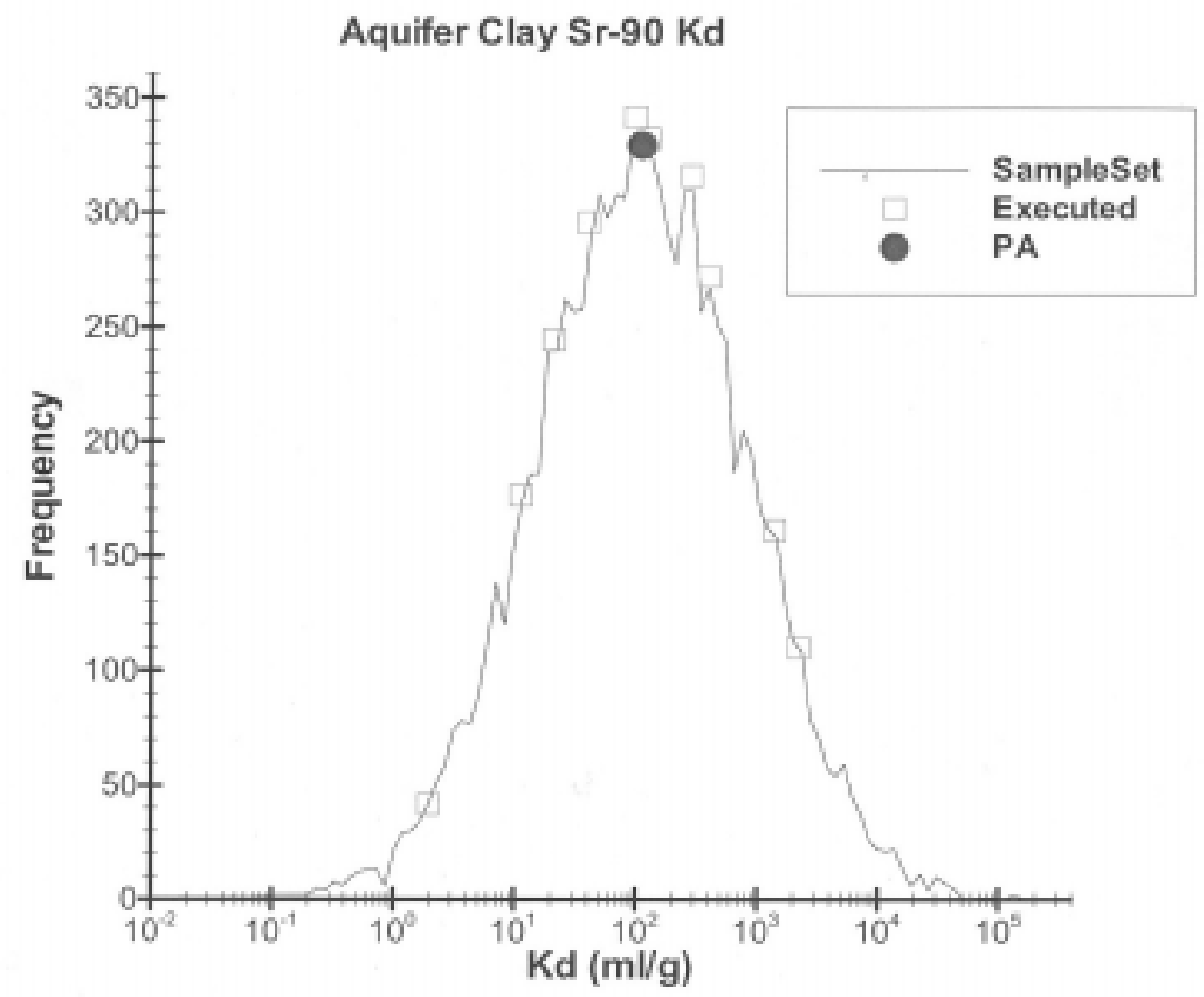

Figure 16. Probability distribution function of aquifer clay $\mathrm{Sr}-90 \mathrm{~K}_{\mathrm{d}}$

Rev. 0 


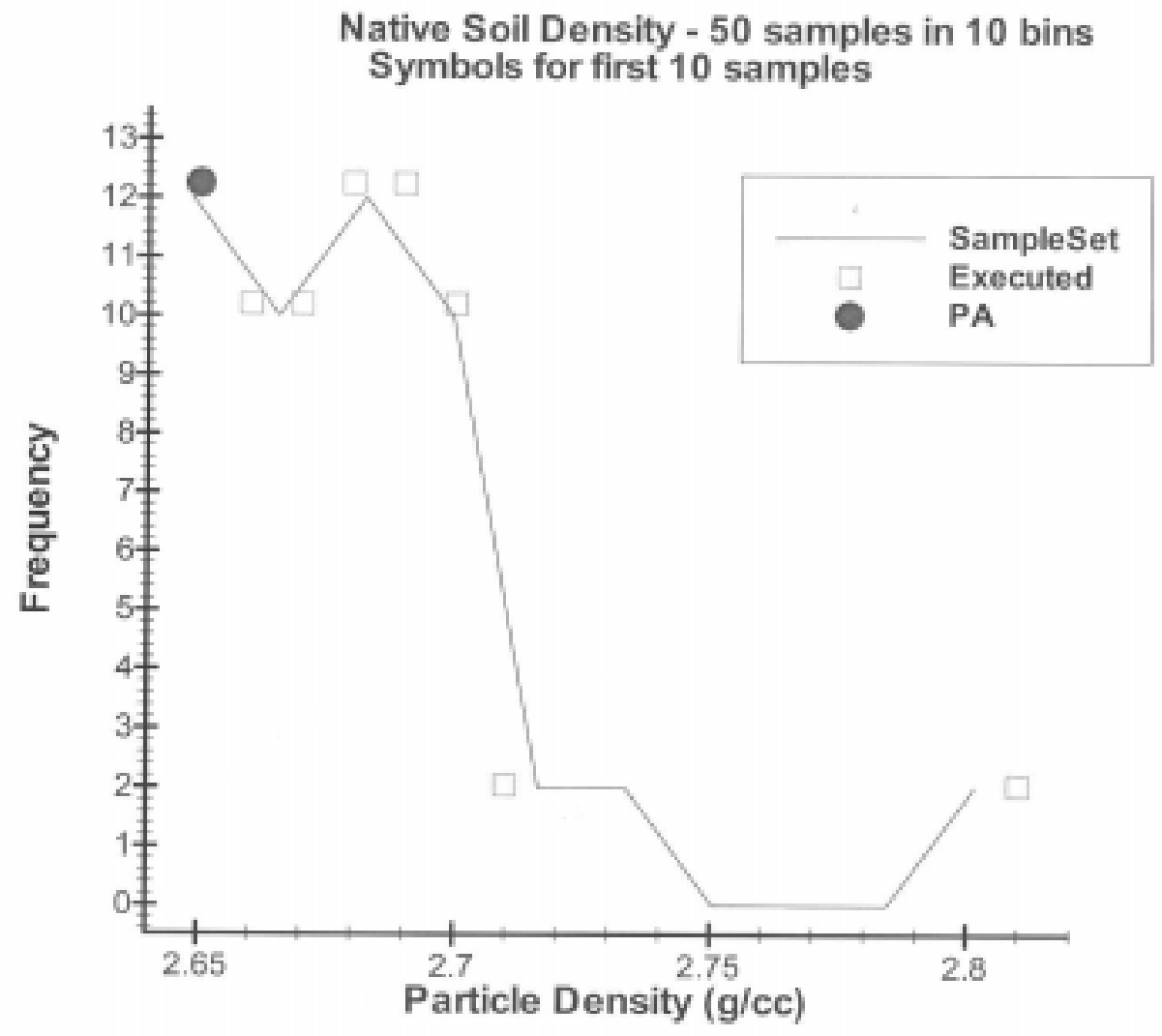

Figure 17. Probability distribution function of native soil density

Rev. 0 


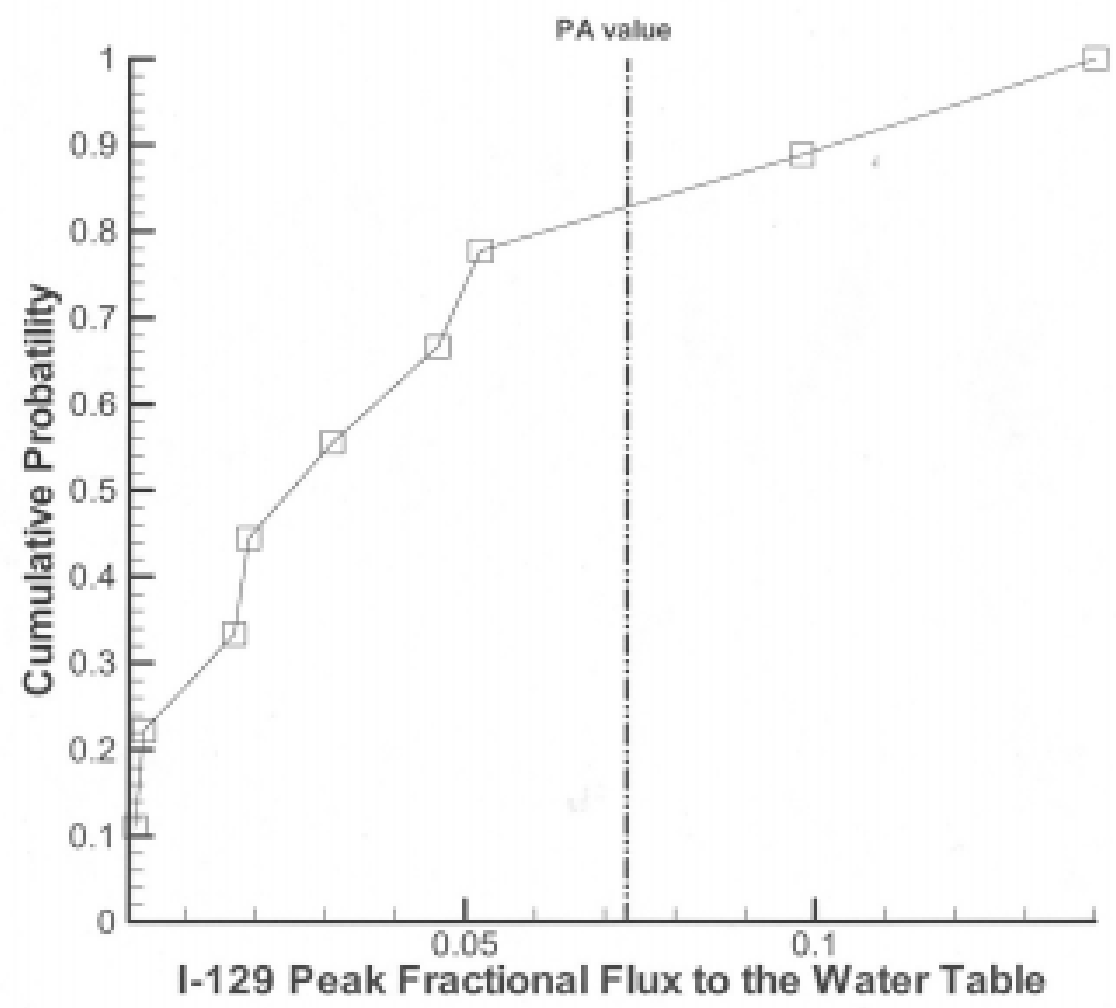

Figure 18. Cumulative probability function of I-129 peak fractional flux to the water table 


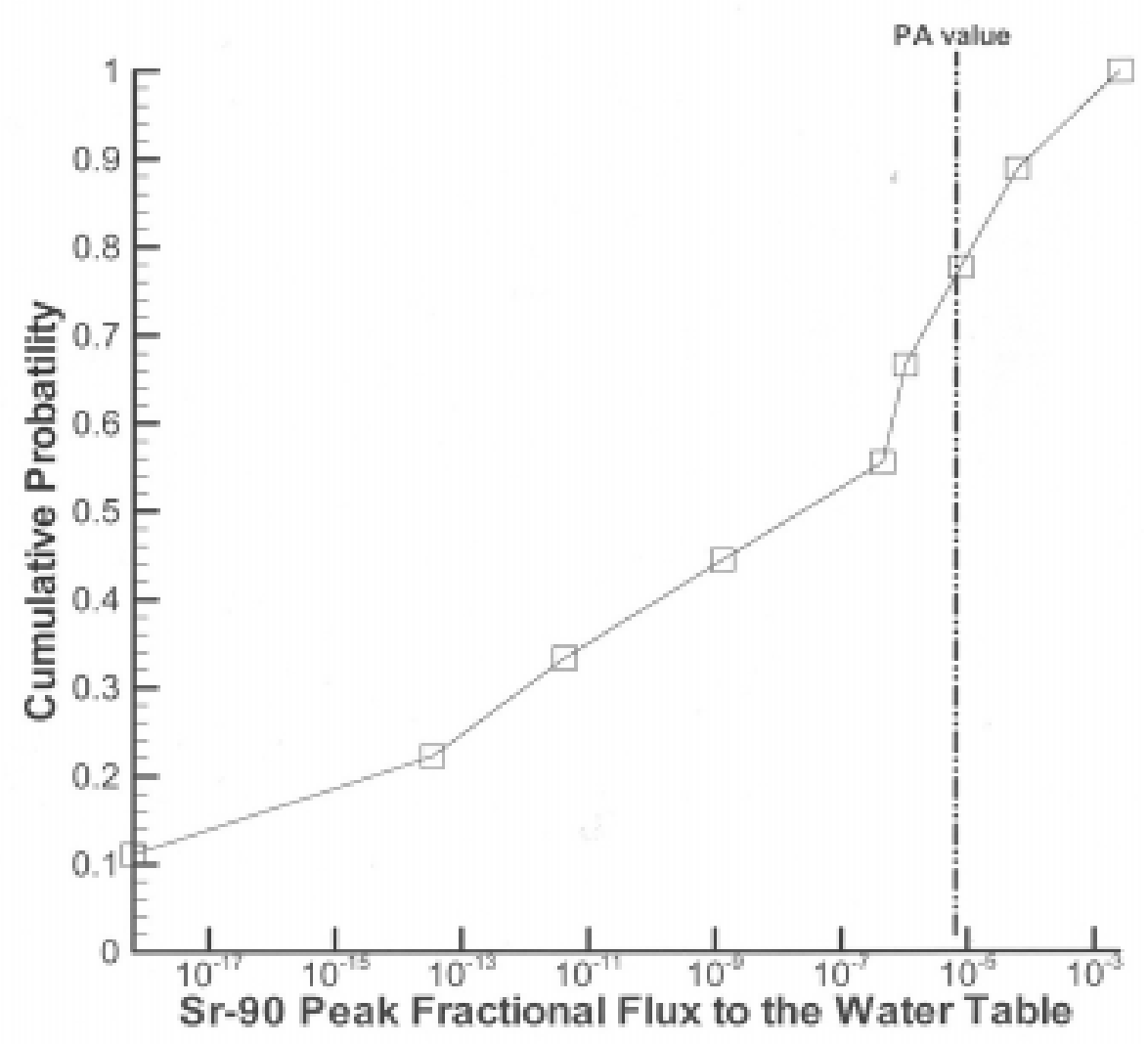

Figure 19. Cumulative probability function of Sr-90 peak fractional flux to the water table 


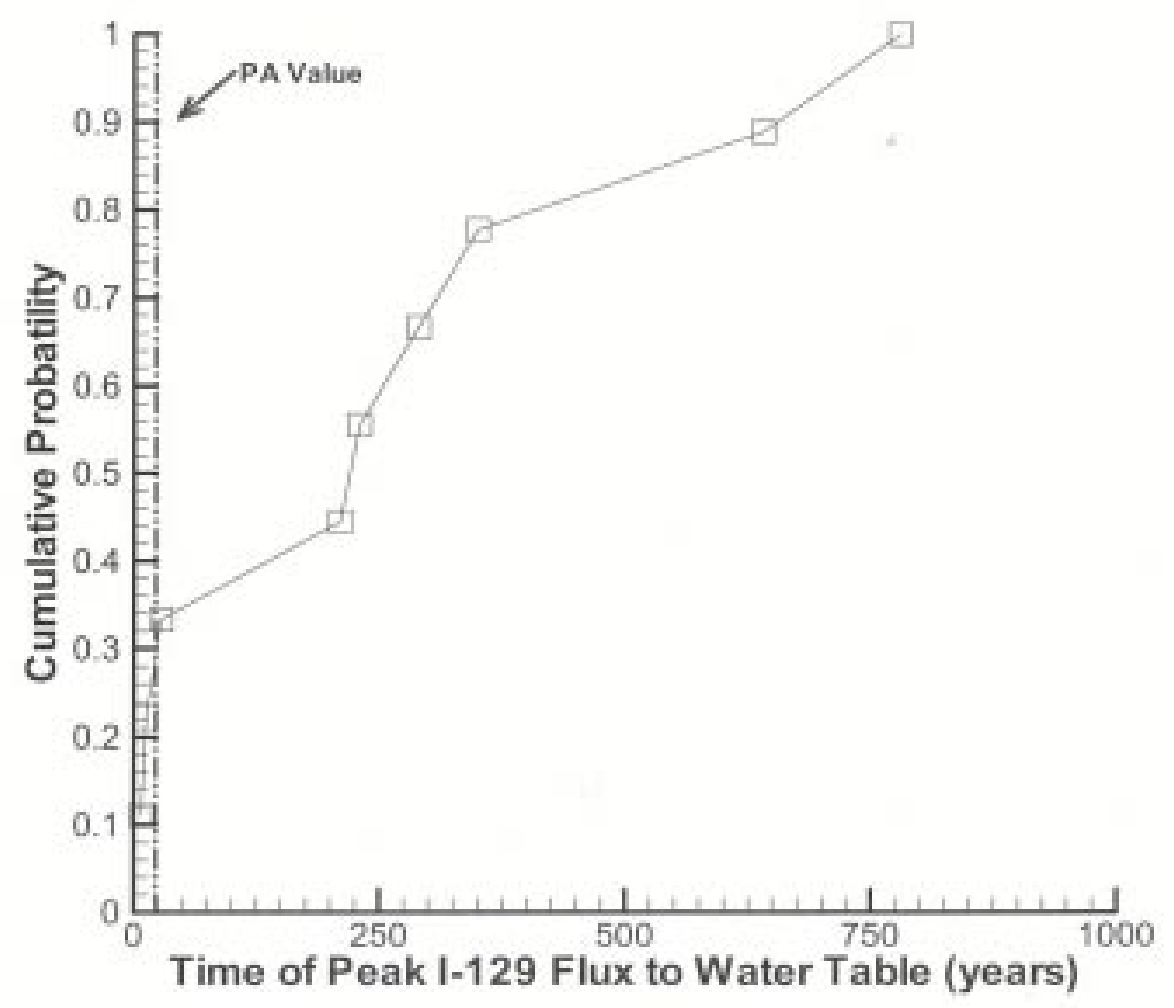

Figure 20. Cumulative probability function of I-129 time of peak flux to the water table 


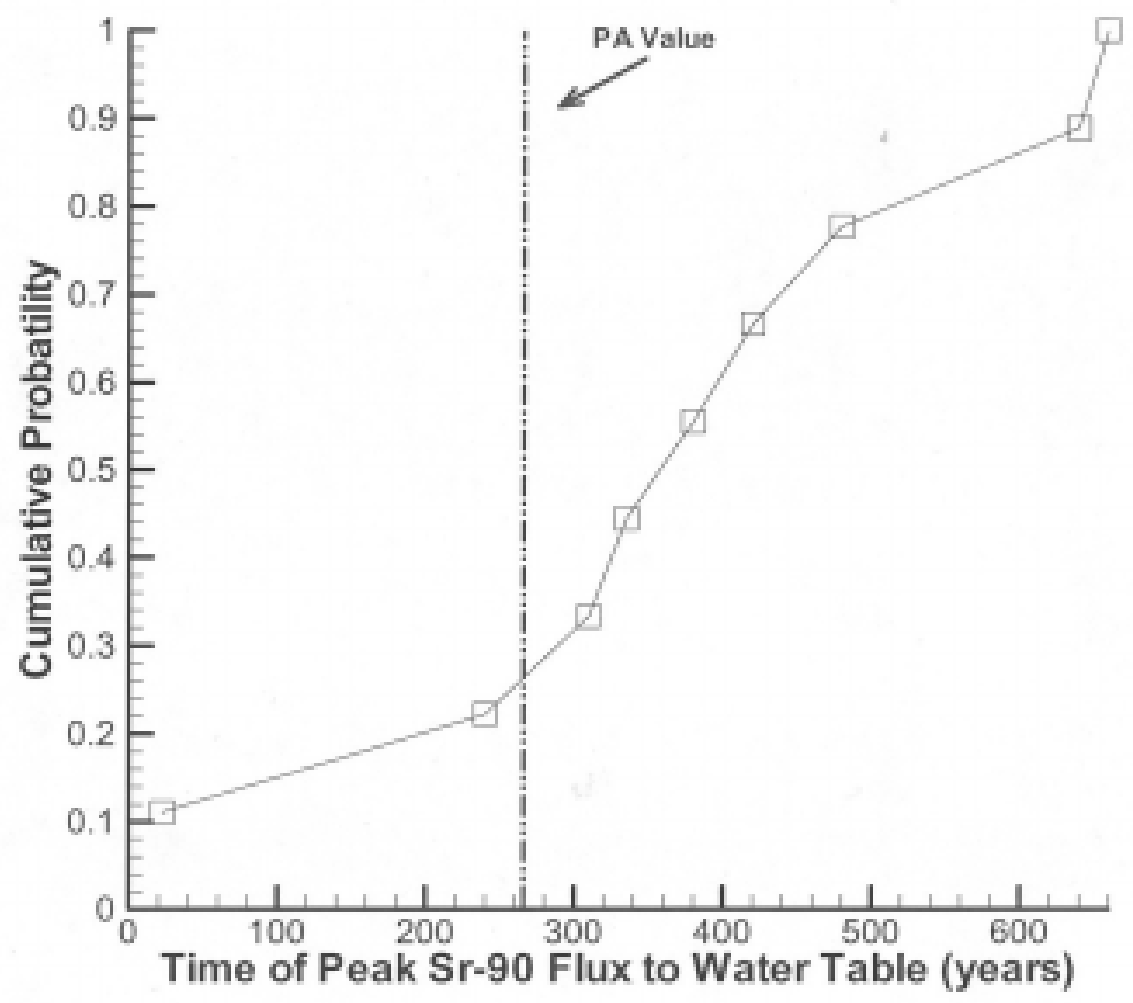

Figure 21. Cumulative probability function of $\mathrm{Sr}-90$ time of peak flux to the water table

Rev. 0 
l-129 Well Concentrations for Peak Curve for Each Sample

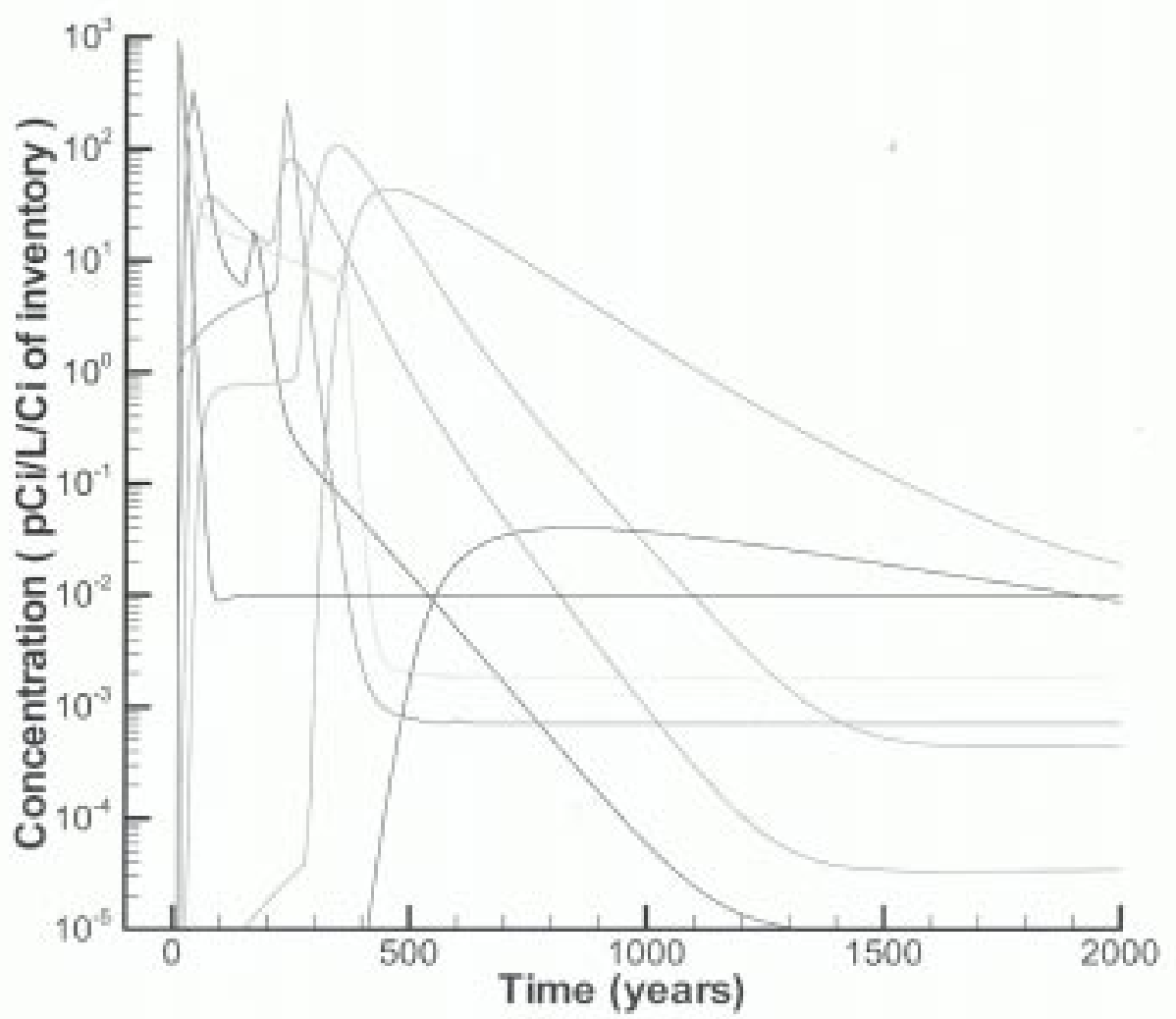

Figure 22. Cumulative probability function of I-129 well concentration versus time

Rev. 0 
Sr-90 well Concentrations for Peak Curve for Each Sample

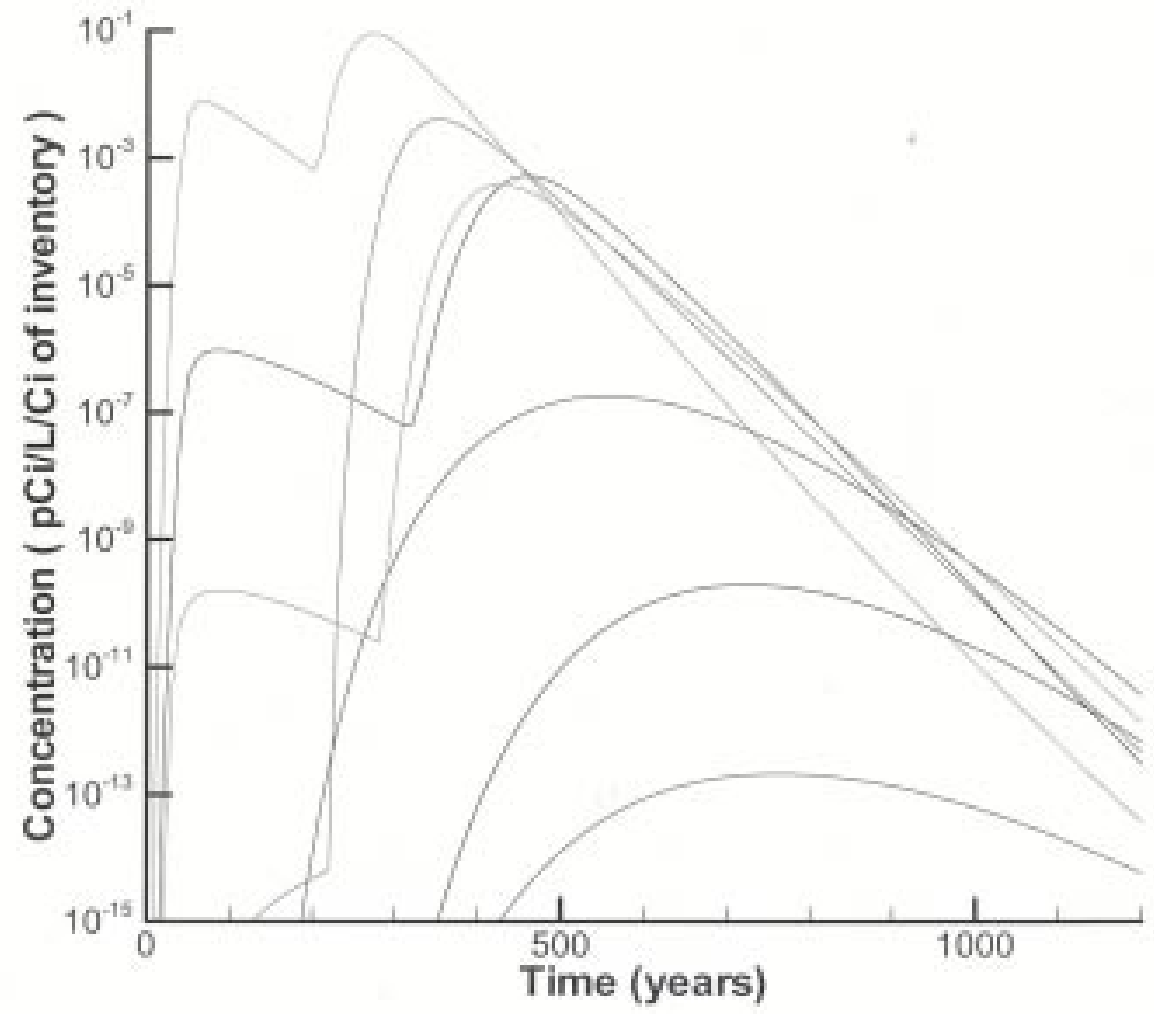

Figure 23. Cumulative probability function of $\mathrm{Sr}-90$ well concentration versus time 


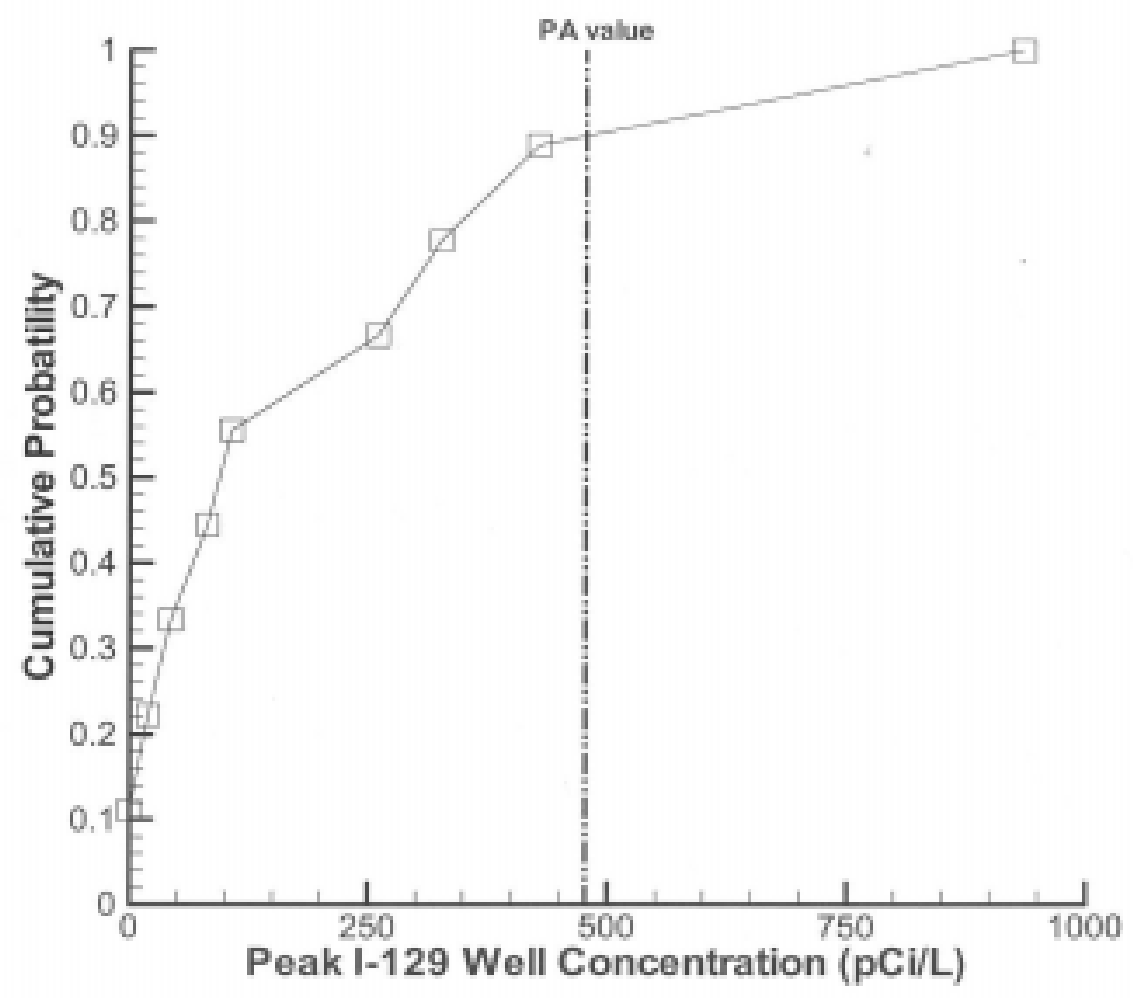

Figure 24. Cumulative probability function of I-129 peak well concentration 


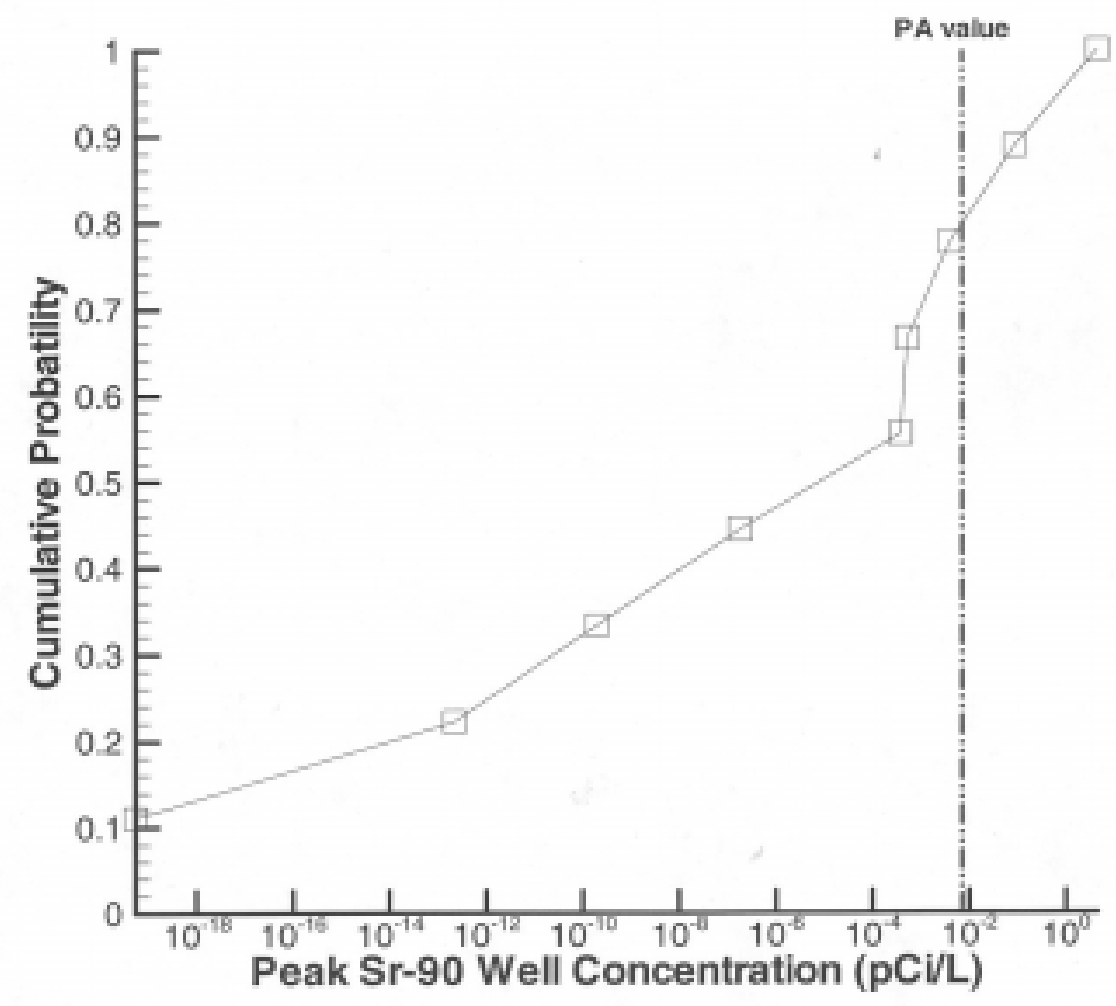

Figure 25. Cumulative probability function of I-129 time of peak well concentration 


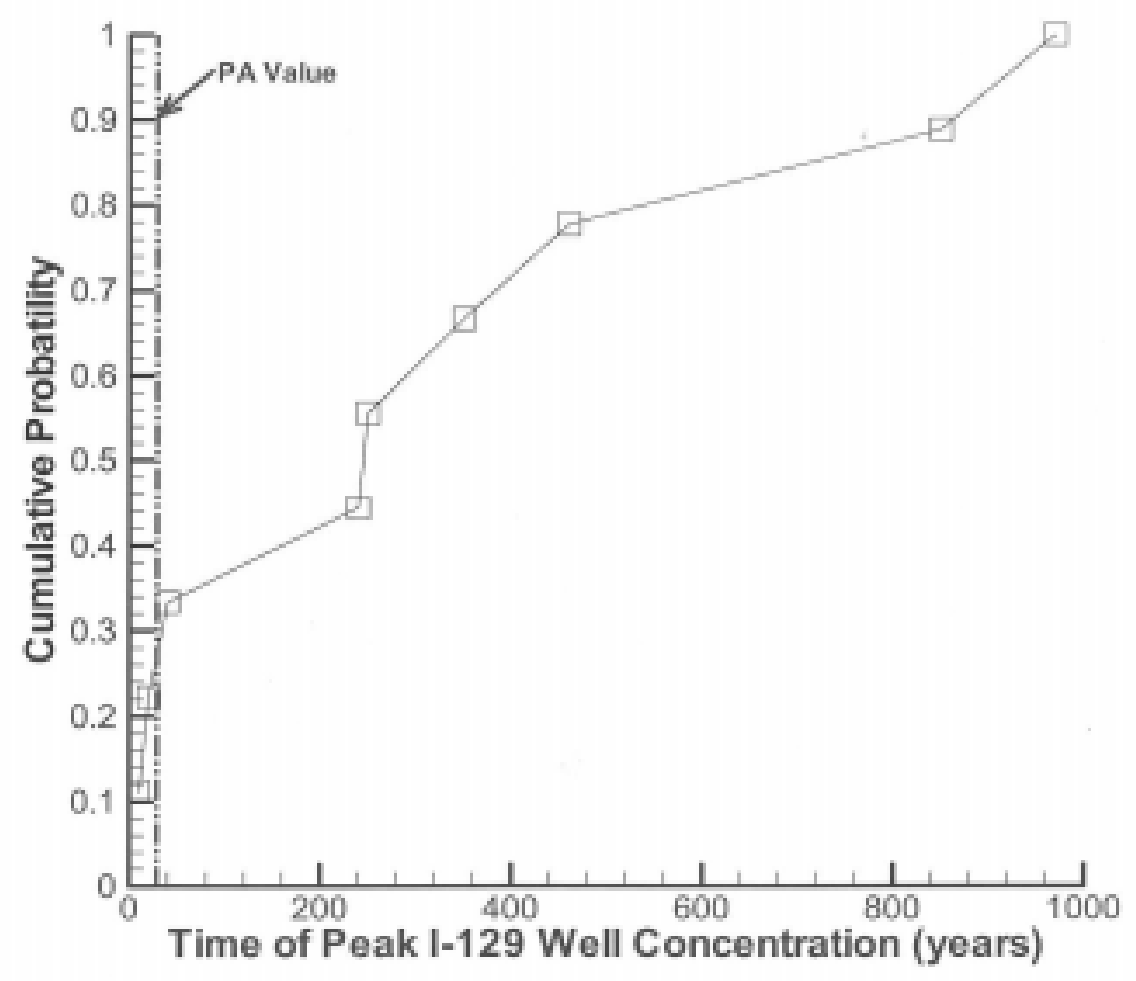

Figure 26. Cumulative probability function of Sr-90 peak well concentration

Rev. 0 


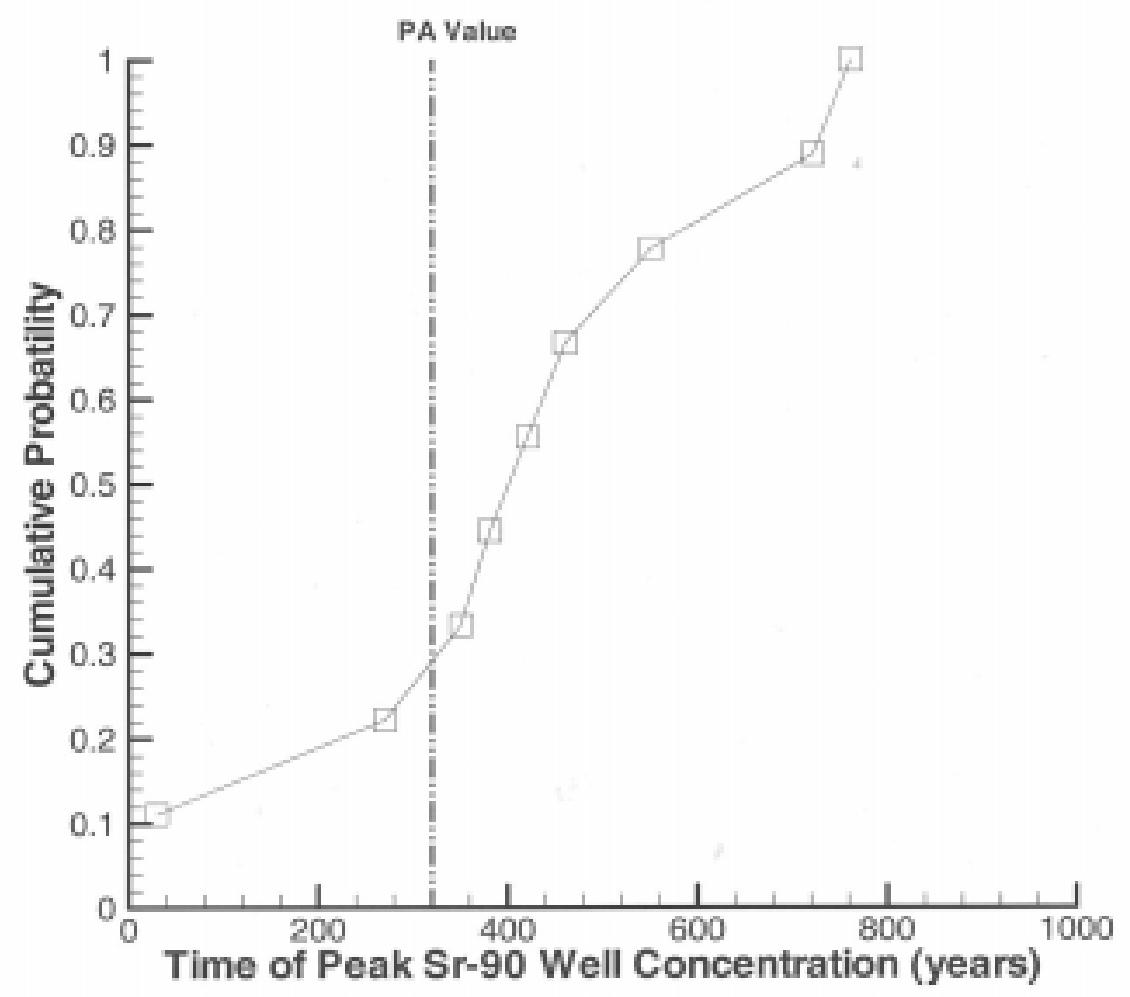

Figure 27. Cumulative probability function of Sr-90 time of peak well concentration 
different computer program than used for the other parts of the program. This model is able to automatically incorporate the site-specific field date maintained in a separate data base. Besides needing to meet convergence and mass balance, the calculated water levels (heads) must come within the range observed in the field. This requires iterative manual interpretation and adjustment for each flow field used in the uncertainty analysis.

Once the flow fields have been established, the transport runs for each species of interest are fairly straight forward. The specific properties for each species must be properly input into the computer program. It is often necessary to adjust some of the solution parameters to satisfy convergence and mass balance requirements.

The unsaturated zone problem is set up as a two dimensional solution. The two-dimensional results must be recast into a three dimensional framework for input into the saturated zone problem.

A typical probabilistic uncertainty analysis usually consists of several thousand realizations, or individual computer runs. In order to do this in a reasonable amount of time, the process must be largely automated. The method of analysis currently used at SRS requires a great deal of "hands on" adjustment.

2. The models used in the PA work at SRS use a great deal of computer time and resources and thus are not ideal for the probabilistic methodology.

The models used in the SRS PA process were selected because they can take into account the processes that are expected to occur in the SRS low-level waste disposal units and the surrounding environment. This means that the computer programs must be able to vary material properties in both space and time. Such programs are necessarily complex and require a great deal of computing power, even with the machines available today. Each run may require several hours to execute and generate an output file several hundred mega-bytes in size. Just managing the machine processing time and storage is a major task. Retrieving the output, determining the significant portions of it, interpreting the results and preparing tables and figures to communicate the results require large amounts of human and computer resources.

3. Significant progress was made in developing tool to automatically run a large number of realizations using the current set of PA models.

A computer program called REPLACER was developed by Leonard Collard to generate the input files needed to make each required realization run. The program allows replacement in a text file similar to a mail-merge program, but it is more sophisticated. The results of a statistical sampling method, such as Monte Carlo or Latin Hypercube, can be read by REPLACER and the input data sets for each realization then created.

4. Even the small number of runs made in doing this work can give some insight into the importance of various parameters on the PA outcome.

To illustrate the potential value of a probabilistic uncertainty analysis, a few observations from the limited study that has been conducted will be made. Because they are based on only a few realizations, these observations have no real value in interpreting or understanding the performance assessment from which they derive. 
Table 8 contains the input values for each of the variable parameters for each case in this study, as well as the results for ${ }^{129} \mathrm{I}$ and ${ }^{90} \mathrm{Sr}$, in terms of peak concentration and the time at which the peak concentration occurs. The cases having the highest and lowest concentration for each radionuclide are discussed below.

\section{Case 9 - Highest ${ }^{129}$ I Concentration}

Case 9 had the highest infiltration rate and the lowest unsaturated zone $K_{d}$ for iodine, which resulted in the highest fractional flux rate at the earliest time. In the saturated zone, this case had the lowest iodine $\mathrm{K}_{\mathrm{d}}$ in sand and the second lowest clay $\mathrm{K}_{\mathrm{d}}$ for iodine. These factors combine to release the entire ${ }^{129} \mathrm{I}$ inventory before the time of cap placement and rapidly transport it to the 100-meter well.

\section{Case 7 - Lowest ${ }^{129}$ I Concentration}

This case produced the lowest ${ }^{129} \mathrm{I}$ concentration because it had the highest iodine $\mathrm{K}_{\mathrm{d}}$ in the native soil in the vadose zone and in the sand of the saturated zone. The high $\mathrm{K}_{\mathrm{d}}$ produces a slow release over a long time period that has a low peak concentration.

\section{Case 7 - Highest ${ }^{90} \mathrm{Sr}$ Concentration}

Though this case produced the lowest ${ }^{129} \mathrm{I}$ concentration, it resulted in the highest concentration for ${ }^{90} \mathrm{Sr}$. As with ${ }^{129} \mathrm{I}$, the outcome is determined by the $\mathrm{K}_{\mathrm{d}}$ that was used for ${ }^{90} \mathrm{Sr}$, which was the lowest of any of the cases run. This resulted in the highest peak fractional flux at the shortest time as well as the highest peak concentration at the 100-meter well at the earliest time.

\section{Case 4 - Lowest ${ }^{90} \mathrm{Sr}$ Concentration}

Two factors combined to give this case the lowest ${ }^{90} \mathrm{Sr}$ concentration, the highest $\mathrm{Sr} \mathrm{K}_{\mathrm{d}}$ in the unsaturated zone and in the sand of the saturated zone, and the longest cap duration of any case. This last factor is especially important for a radionuclide with a relatively short half life, such as ${ }^{90} \mathrm{Sr}$.

The observations from the four examples above are more of a sensitivity analysis than an uncertainty analysis. Many more realizations are required to be able to fully appreciate the interaction of the variations in all of the parameters on the results and thus give the insight into the nature of the overall disposal system and the performance assessment process that is the goal of a probabilistic uncertainty analysis.

5. The few runs that were made indicate that the PA results have higher concentrations at earlier times than most of the realizations selected.

Figures 24 through 27 show that the concentrations at the 100 meter well calculated in the PA are greater, and the time of peak concentration is less than most of the realizations run in this study. With as few runs as were made in this study, it is impossible to draw any conclusion. If similar results were found after hundreds or thousands or realizations, the conclusion that the PA was conservative could easily be justified. 
Table 8. Case by Case Parameters and Results

\begin{tabular}{|c|c|c|c|c|c|c|c|c|c|c|}
\hline \multirow[t]{2}{*}{ Parameter } & \multicolumn{10}{|c|}{ Case } \\
\hline & PA & 1 & 2 & 3 & 4 & 5 & 6 & 7 & 8 & 9 \\
\hline \multicolumn{11}{|c|}{ Vadose Zone } \\
\hline Infiltration & 40 & 33.1 & 41.6 & 34.3 & 41.6 & 35.5 & 37.7 & 49.8 & 39.2 & 57.6 \\
\hline Density $(\mathrm{g} / \mathrm{cc})$ & 2.65 & 2.70 & 2.68 & 2.67 & 2.71 & 2.69 & 2.65 & 2.66 & 2.67 & 2.81 \\
\hline Porosity & 0.42 & 0.42 & 0.39 & 0.41 & 0.377 & 0.378 & 0.482 & 0.429 & 0.41 & 0.47 \\
\hline Sat K (cm/yr) & 315.4 & 1041 & 2176.9 & 2494.7 & 2176.9 & 315.6 & 1420.8 & 2052.7 & 18920.0 & 1450.0 \\
\hline $\begin{array}{l}\text { Soil Suction } \\
\text { Case }\end{array}$ & PA & $\begin{array}{l}\text { AT N } \\
14-16\end{array}$ & $\begin{array}{l}\text { AT N } \\
28-30\end{array}$ & $\begin{array}{l}\text { AT } 8 \\
41-43\end{array}$ & $\begin{array}{l}\text { AT } 8 \\
4-6\end{array}$ & $\begin{array}{l}\text { AT } 8 \\
13-15\end{array}$ & $\begin{array}{l}\text { AT N } \\
18-20\end{array}$ & $\begin{array}{l}\text { AT N } \\
23-25\end{array}$ & $\begin{array}{l}\text { AT N } \\
42-44\end{array}$ & $\begin{array}{l}\text { AT N } \\
51-53\end{array}$ \\
\hline Cap Time (yr) & 25.0 & 40.3 & 42.2 & 36.4 & 13.7 & 49.2 & 6.1 & 22.7 & 29.3 & 26 \\
\hline $\begin{array}{l}\text { Cap Duration } \\
\text { (yr) }\end{array}$ & 100 & 268 & 149 & 104 & 322 & 201 & 208 & 206 & 243 & 154 \\
\hline \multicolumn{11}{|l|}{ Aquifer } \\
\hline Sand Density & 2.65 & 2.65 & 2.65 & 2.65 & 2.65 & 2.65 & 2.65 & 2.65 & 2.65 & 2.65 \\
\hline Sand Porosity & 0.25 & 0.15 & 0.175 & 0.20 & 0.225 & 0.25 & 0.275 & 0.30 & 0.325 & 0.35 \\
\hline Clay Density & 2.65 & 2.65 & 2.65 & 2.65 & 2.65 & 2.65 & 2.65 & 2.65 & 2.65 & 2.65 \\
\hline Clay Porosity & 0.25 & 0.15 & 0.175 & 0.20 & 0.225 & 0.25 & 0.275 & 0.30 & 0.325 & 0.35 \\
\hline \multicolumn{11}{|l|}{ I-129 } \\
\hline \multicolumn{11}{|l|}{ Vadose Zone } \\
\hline Flow Case & PA & $10^{*}$ & 6 & 9 & 6 & 4 & 2 & 7 & 3 & 1 \\
\hline $\mathrm{Kd}(\mathrm{ml} / \mathrm{g})$ & 0.6 & 12.5 & 1.73 & 0.56 & 0.13 & 2.21 & 0.3 & 30.0 & 6.54 & 0.001 \\
\hline $\begin{array}{l}\text { Peak Frac. } \\
\text { Flux }\end{array}$ & 7.3E-2 & $4.1 \mathrm{E}-3$ & $3.1 \mathrm{E}-2$ & $5.2 \mathrm{E}-2$ & $9.8 \mathrm{E}-2$ & $1.9 \mathrm{E}-2$ & $4.6 \mathrm{E}-2$ & $2.9 \mathrm{E}-3$ & $1.7 \mathrm{E}-2$ & $1.4 \mathrm{E}-1$ \\
\hline Time (yr) & 22.4 & 640 & 210 & 28 & 12.7 & 290 & 230 & 780 & 350 & 7.3 \\
\hline \multicolumn{11}{|l|}{ Aquifer } \\
\hline Flow Case & PA & 8 & 6 & 9 & 6 & 4 & 2 & 7 & 3 & 1 \\
\hline $\begin{array}{l}\text { VZ Transport } \\
\text { Case }\end{array}$ & PA & 1 & 2 & 3 & 4 & 5 & 6 & 7 & 8 & 9 \\
\hline Sand Kd & 0.6 & 12.5 & 1.73 & 0.57 & 0.125 & 2.21 & 0.30 & 30.0 & 6.54 & $1.1 \mathrm{E}-2$ \\
\hline Clay Kd & 1.0 & 2.94 & 4.09 & 11.01 & 0.372 & 1.62 & 0.13 & 1.11 & 1.91 & 0.69 \\
\hline $\begin{array}{l}\text { Peak Conc } \\
(\mathrm{pCi} / \mathrm{L})\end{array}$ & 477 & 19.7 & 81.6 & 326 & 428 & 107 & 260 & 10.3 & 43.5 & 935 \\
\hline Time (yr) & 29 & 970 & 250 & 40 & 20 & 350 & 240 & 1260 & 460 & 10 \\
\hline \multicolumn{11}{|l|}{ Sr-90 } \\
\hline \multicolumn{11}{|l|}{ Vadose Zone } \\
\hline Flow Case & $\mathrm{PA}$ & $10^{*}$ & 6 & 9 & 6 & 4 & 2 & 7 & 3 & 1 \\
\hline $\mathrm{Kd}(\mathrm{ml} / \mathrm{g})$ & 10.0 & 3.88 & 3.10 & 24.1 & 288 & 31.9 & 7.35 & 0.55 & 9.21 & 95.8 \\
\hline $\begin{array}{l}\text { Peak Frac. } \\
\text { Flux }\end{array}$ & $9.2 \mathrm{E}-6$ & $4.4 \mathrm{E}-7$ & $5.9 \mathrm{E}-5$ & $1.3 \mathrm{E}-9$ & $6.3 \mathrm{E}-19$ & $4.2 \mathrm{E}-12$ & $7.5 \mathrm{E}-6$ & $2.5 \mathrm{E}-3$ & $1.0 \mathrm{E}-6$ & $3.4 \mathrm{E}-14$ \\
\hline Time (yr) & 266 & 420 & 240 & 480 & 335 & 640 & 310 & 22.7 & 380 & 660 \\
\hline Flow Case & PA & 8 & 6 & 9 & 6 & 4 & 2 & 7 & 3 & 1 \\
\hline $\begin{array}{l}\text { VZ Transport } \\
\text { Case }\end{array}$ & PA & 1 & 2 & 3 & 4 & 5 & 6 & 7 & 8 & 9 \\
\hline Sand Kd & 10 & 3.88 & 3.10 & 24.1 & 288.0 & 31.9 & 7.35 & 0.55 & 9.21 & 95.9 \\
\hline Clay Kd & 110 & 1374. & 282.5 & 1.95 & 21.0 & 40.2 & 98.8 & 2211. & 11.3 & 124.9 \\
\hline $\begin{array}{l}\text { Peak Conc } \\
(\mathrm{pCi} / \mathrm{L})\end{array}$ & $7.0 \mathrm{E}-3$ & $5.3 \mathrm{E}-4$ & $8.9 \mathrm{E}-2$ & $1.8 \mathrm{E}-7$ & $5.4 \mathrm{E}-20$ & $2.0 \mathrm{E}-10$ & $4.0 \mathrm{E}-3$ & $4.7 \mathrm{E} 0$ & $3.8 \mathrm{E}-4$ & $2.2 \mathrm{E}-13$ \\
\hline Time $(\mathrm{yr})$ & 320 & 460 & 271 & 551 & 381 & 722 & 350 & 30 & 421 & 762 \\
\hline
\end{tabular}

Note: all vadose zone values that are material dependent are for "Native Soil" only

*Vadose zone flow case 8 resulting in ponding, so it was replaced by case 10 


\section{RECOMMENDATIONS}

The first two conclusions in the previous section relate to the complexity of the PA process as implemented at SRS and how it makes the use of probabilistic methods very difficult. There are three possibilities to address this issue. The first is to further develop pre- and post-processors with the goal of automating the present set of computer programs to facilitate running the thousands of realizations needed for a full probabilistic uncertainty analysis. The second is to find a new computer program or programs that can account for all of the physical and chemical process in the present set of codes, but that is amenable to the requirements of probabilistic analyses. The third is to use computer programs built around analytic solutions to perform probabilistic analyses.

The first possibility has the advantage it would make use of the existing computer programs and would thus maintain the ability to account for all of the processes included in the PA. The resulting methodology might take many CPU-months to make the runs, but it would be with minimal human intervention. However, evaluation and interpretation of such a massive data set would take substantial resources.

If we wish to change our current philosophy and switch to a probabilistic analysis to demonstrate compliance, then it would be advantageous to select the second possibility and find programs which have been designed to facilitate probabilistic analyses and which can account for the physical and chemical processes found at SRS disposal facilities. Once such computer programs were found, they would have to be benchmarked against the existing programs.

The third possibility, and the one recommended by SRTC, is the use of another single or set of computer programs, typically based on analytic solutions, that have been developed specifically to do probabilistic uncertainty analyses. These types of programs typically have probability density functions for each of the parameters to be varied as input, and have a statistical sampling protocol built into the program. Use of analytical solutions usually means that spatially and temporally varying properties cannot be used.

SRTC recommends the following actions with remaining funding this fiscal year:

1. Survey other major DOE disposal sites that have done performance assessments to see what efforts they have made in developing probabilistic uncertainty capabilities.

2. Investigate candidate programs developed specifically to do probabilistic uncertainty analyses and make a recommendation for one to use at SRS.

3. Prepare a program plan that outlines the major elements for conducting probabilistic uncertainty analyses using the recommended approach. 


\section{REFERENCES}

Aadland, R. K., J. A. Gellici and P. A. Thayer, 1995, Hydrogeological framework of west-central South Carolina, South Carolina Department of Natural Resources, Water Resources Division Report 5, 200 p. +47 plates.

Carsel, R. F. and R. S. Parrish, 1988. Developing joint probability distributions of soil water retention characteristics. Water Resources Research, 24:755-769.

Cook, J. R. and L. B. Collard, 2001, Program plan for developing methodology for probabilistic uncertainty analysis, WSRC-RP-2001-00389, Rev. 0.

Crowe, Bruce. 2002. Probabilistic Modeling: Applications to Performance Assessment Maintenance Plan Studies for Low-Level Waste Disposal Facilities. Report for DOE LFRG.

Decisioneering, Inc., Crystal Ball 2000 Users Manual. Decisioneering, Inc. Denver, Co, 2000.

Dennehy, K. F. and P. B. McMahon, 1987. Water Movement in the Unsaturated Zone at a LowLevel Radioactive-Waste Burial Site Near Barnwell, South Carolina. U.S. Geological Survey Open-File Report 87-46.

Flach, G. P., 1998, Impact of F- and H-area pump-treat-reinject remediation systems on the Old Radioactive Waste Burial Ground (U), SRT-EST-98-154.

Flach, G. P. and M. K. Harris, 1999, Integrated hydrogeological modeling of the General Separations Area; Volume 2; Groundwater flow model (U), WSRC-TR-96-0399, Rev. 1.

Flach, G. P., M. K. Harris, R. A. Hiergesell, A. D. Smits and K. L . Hawkins, 1999, Regional groundwater flow model for the C, K, L, and P Reactor Areas, Savannah River Site, Aiken, South Carolina (U), WSRC-TR-99-00248, Rev. 0.

Hamm, L. L. and S. E. Aleman, 2000, FACT (version 2.0); Subsurface flow and contaminant transport documentation and user's guide (U), WSRC-TR-99-00282.

Holmes-Burns, Heather, 2001. E-Area 1999-2001 Vadose Zone Monitoring System Program Annual Summary Report. SWD-SWE-2001-00104. September 2001

Hubbard, J. E. and M. Englehardt, 1987. Calculation of Groundwater Recharge at the Old SRP Burial Ground Using the CREAMS Model (1961-1986). E. I. Du Pont de Nemours \& Co., Savannah River Laboratory, Aiken, SC, September.

McDowell-Boyer, Laura, Andrew D. Yu, James R. Cook, David C. Kocher, Elmer L. Wilhite, Heather Holmes-Burns and Karen E. Young, Radiological Performance Assessment for the EArea Low-Level Waste Facility, WSRC-RP-94-218, Rev. 1. Westinghouse Savannah River Company, Aiken, South Carolina. January 31, 2000.

Morgan, M. G. and M. Henrion, 1990, Uncertainty; A guide to dealing with uncertainty in quantitative risk and policy analysis, Cambridge University Press. 
Parizek, R. R. and R. W. Root, 1986. Development of a Ground-Water Velocity Model for the Radioactive Waste Management Facility, Savannah River Plant, South Carolina. College of Earth and Mineral Sciences, Pennsylvania State University, University Park, PA.

Rawls, W. J., D. L. Brakensiek and K. E. Saxton, 1982. Estimating soil water properties. Transactions, ASAE, 25(5):1316-1320 and 1328.

Sheppard, Marsha I. and Thibault, D. H., 1990. Default Solid/Liquid Partition Coefficients, $K_{d} s$ for Four Major Soil Types: A Compendium. Health Physics 59.4:471-482.

U. S. DOE. 1999a. Radioactive Waste Management, Order 435.1, U. S. Department of Energy.

U. S. DOE, 1999b. Maintenance Guide for U.S. Department of Energy Low-Level Waste Disposal Facility Performance Assessments and Composite Analyses, U.S. Department of Energy, November 10, 1999.

Van Genuchten, M. Th., F. J. Leij and S. R. Yates, 1991. The RETC Code for Quantifying the Hydraulic Functions of Unsaturated Soils. EPA/600/2-91/065. U. S. Environmental Protection Agency, Ada, OK. 
THIS PAGE INTENTIONALLY LEFT BLANK

Rev. 0 


\section{DISTRIBUTION}

V. W. Sauls, 703-A

H. L. Pope, 703-A

W. Smith, 703-A

P. I. Hudson, 705-3C

W. T. Goldston, 705-3C

D. F. Sink. 724-15E

K. L. Tempel, 724-15E

S. R. Reed, 724-9E

W. E. Stevens, 773-A

B. T. Butcher, 773-43A

E. L. Wilhite, 773-43A

M. K. Harris, 773-42A

J. B. Gladden, 773-42A

P. L. Lee, 773-42A

G. P. Flach, 773-42A

L. B. Collard, 773-43A

J. R. Cook, 773-43A

STI

WDED Files 